\title{
CONFIGURACIÓN DEL BARRIO MUTIS Y DIAGNÓSTICO DE SU ZONA DE MAYOR TRANSFORMACIÓN: LA CARRERA 2W
}

Wendy Yurany Henao Pineda*

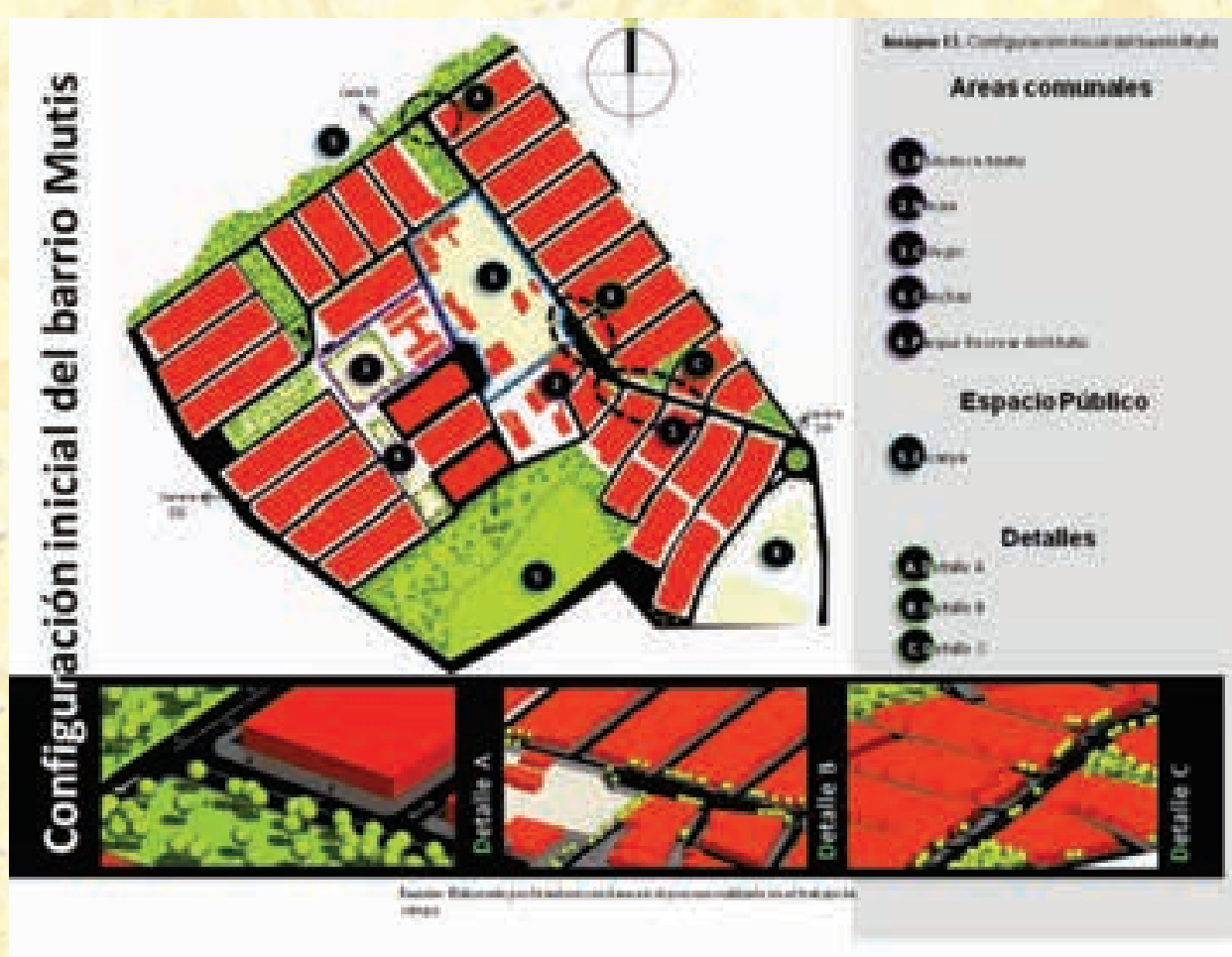

Imagen A. Configuracio
Mutis. Fuente: Autora

\section{RESUMEN}

El propósito de esta investigación consistió en determinar la composición del barrio Mutis de Bucaramanga, su estructura urbana y la transformación de su eje de mayor actividad: la Carrera 2W. De esta manera fue posible reconocer el barrio desde lo funcional y espacial, para lograr la comprensión de su estructura, funcionamiento y transformación de espacios como producción social, amparados en la teoría planteada por Henry Lefebvre para quien el espacio es una construcción social en la que cada sociedad al relacionarse, produce su espacio propio, el cual se transforma como una expresión social de quienes lo habitan. A través del diagnóstico del barrio Mutis y de su eje de mayor importancia, la Carrera 2W, se determinaron los impactos que afectaron la vía debido a un mega proyecto vial, proponiéndose para ello, estrategias de mitigación de dichos impactos.

\section{PALABRAS CLAVE}

Bucaramanga, Barrio Mutis, Carrera 2W. 


\section{THE CONFIGURATION OF MUTIS NEIGHBORHOOD AND DIAGNOSIS OF ITS MAJOR TRANSFORMATION AREA: THE STREET 2W}

Wendy Yurany Henao Pineda*

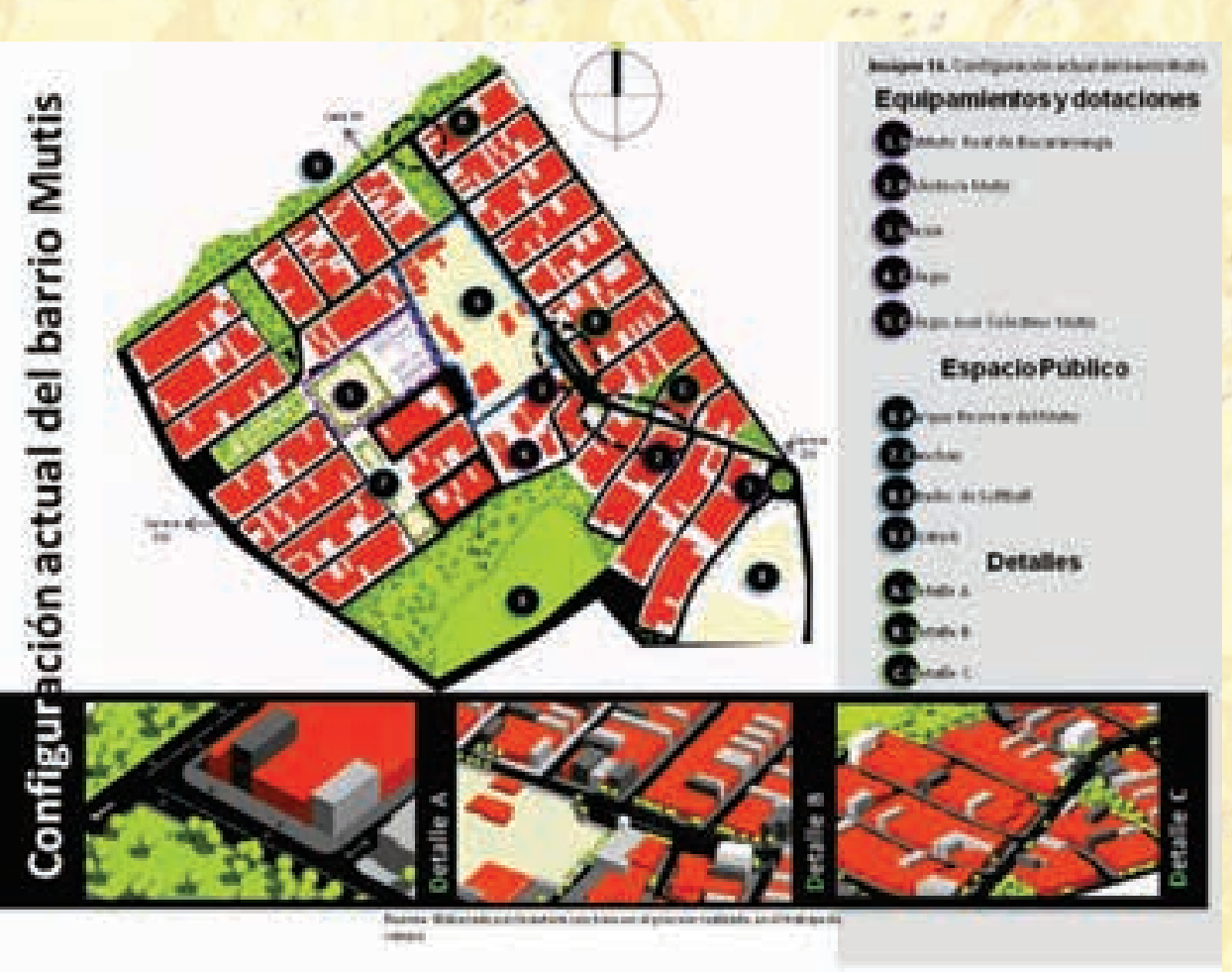

\section{ABSTRACT}

The purpose of this investigation was to determine the composition of the neighborhood Mutis Bucaramanga, its urban structure and the transformation of its main activity axis: the street $2 \mathrm{~W}$. Thus, it was possible to recognize the neighborhood on a functional and spacial basis in order to understand its structure, function and transformation upon the theory put forth by Henry Lefebvre for whom space is a social construction in which each society by interacting produces its own space, which transforms as a social expression of those who inhabit it. Them, through the diagnosis of Mutis neighborhood and its axis of main importance, the street $2 \mathrm{~W}$, the impacts that affected street were identified, due to a mega road project, and therefore led to propose a set of strategies mitigation.
Este artículo es producto de la investigación realizada para optar por el título de arquitecta en la Facultad de Arquitectura de la Universidad Santo Tomás, seccional Bucaramanga, la cual fue Laureada. En él sólo se presenta la primera etapa de la investigación denominada Configuración del área de influencia, pues la etapa Il correspondiente al Diagnóstico del área de intervención, se publicará en una próxima entrega de la Revista.

* El proyecto fue dirigido por el arquitecto Jorge Alberto Villamizar Hernández, especialista en Docencia Universitaria y en Proyectos arquitectónicos
Imagen B. Configuración actual del barrio Mutis. Fuente: Autora

\section{KEY WORDS:}

Bucaramanga, Mutis neighborhood, Street 2W. 


\section{INTRODUCCIÓN}

Este proyecto de investigación partió de un interés por contrastar con la realidad inmediata, uno de los conceptos ideológicos expuestos por el filósofo y sociólogo marxista Henry Lefébvre, desarrollado en sus estudios urbanísticos y sobre la ciudad. Se ha querido tomar de este autor la definición de ciudad, concebida como "la proyección de la sociedad global sobre el terreno"', concepto estudiado en las cátedras de Análisis y Proyecto Urbano Ambiental de la Facultad de Arquitectura, trabajado ampliamente en varias de sus obras entre las que se encuentran El derecho a la ciudad I y Espacio y política, El derecho a la ciudad II publicado en 1972, obra en la que se detallan y explican cada una de las categorías de espacio, desde la más inmediata a la percepción, hasta la más compleja, la cual fue el objeto de nuestro estudio; es decir, el espacio como construcción social en el que cada sociedad al relacionarse, produce un espacio propio que poco a poco transforma como expresión social de quienes lo habitan.

Con la intención de poner en práctica la contrastación y descripción empírica de la que habla Lefebvre en nuestro entorno, se elige como referente para esta investigación el barrio Mutis, uno de los barrios más tradicionales y, a su vez, mejor conformados, al ser ordenador de la trama urbana del municipio de Bucaramanga, considerado hasta hoy como un ejemplo de organización, en tanto da respuesta al problema de la vivienda y equipamientos como unidad habitacional; de allí surge el interés de hacer un estudio detallado de la zona de mayor transformación, determinada en esta investigación como la Carrera 2W. Mediante visitas de campo se recopiló información sobre la geomorfología del barrio, trama urbana, usos y actividades, tejido edilicio, espacio público, infraestructura vial, movilidad y accesibilidad, entre otras categorías que fueron dispuestas en fichas de análisis, que permitieron cumplir el objetivo trazado en el trabajo, es decir, realizar un estudio acerca del desarrollo histórico del barrio y determinar su composición, estructura urbana y transformación de su eje de mayor actividad: la Carrera 2W. De esta manera fue posible reconocer el barrio desde lo funcional y espacial, para lograr la comprensión de su estructura, funcionamiento y transformación de espacios como producción social.

El desarrollo de la investigación permitió encontrar que el eje de transformación del barrio, objeto de nuestro análisis primario, sería intervenido a corto plazo por la administración municipal, para ejecutar un nuevo proyecto de movilidad vial el cual generaría una serie de transformaciones y/o afectaciones, que más allá de ser producto de la construcción social mencionada por Lefebvre, son más bien producto de lo que él mismo en su tercera hipótesis llama el espacio usado como instrumento político dirigido deliberadamente y acotado:

"se trata de un procedimiento en manos de alguien, individuo o colectividad, es decir, de un poder (por ejemplo, de un Estado), de una clase dominante (la burguesía) o de un grupo que puede, en ciertas ocasiones, representar a la sociedad global y en otras a tener sus objetivos propios, el cual implica el proyecto, la estrategia".

Habida cuenta que nuestro compromiso como arquitectos implica proponer soluciones alternativas para la conservación y el mejoramiento de la calidad de vida de los habitantes de cada espacio, se determina que el alcance de esta investigación, fuese la elaboración de un conjunto de recomendaciones como alternativa de mitigación de los impactos generados

\footnotetext{
LEFEBVRE, Henry. El derecho a la ciudad. Barcelona, Edicione s península, 1978. p. 10

2 VAZQUEZ, Antonio. Los aportes de Lefbvre a la geografía urbana. Un corpus teórico para entender las nuevas espacialidades. México, Colegio de geografía UNAM, 2009. p.5
} 
con la realización de dicho proyecto. Si bien la administración pública local, debe ser la responsable de la concepción, planeamiento, reglamentación y control del espacio público que se requiere para un apropiado funcionamiento de las áreas urbanas, y la procura de una alta calidad de vida en la ciudad, somos conscientes, pues así se percibió en el desarrollo de la investigación, de la inclinación de las administraciones municipales, por el planeamiento urbano carente de rigor, en el cual se propone cómo deben ser las ciudades sin profundizar en el análisis de cómo son, que evidencia una carencia de interés institucional por efectuar investigaciones y estudios previos que evalúen los impactos posteriores, no sólo de este proyecto sino de la mayoría de los que se deciden ejecutar a nivel local, regional y nacional, por lo que pretendemos que investigaciones como ésta sirvan como herramienta para la toma de decisiones en futuros proyectos que afecten la transformación natural de los espacios urbanos $y$, por tanto, la calidad de vida de quienes los habitan.

\section{DEFINICIÓN DEL PROBLEMA}

El Barrio Mutis, ubicado al Noroccidente la ciudad de Bucaramanga, fue fundado hace 44 años y pese a las transformaciones como expresión de sus habitantes en búsqueda de satisfacer sus necesidades básicas, su trama urbana permanece casi intacta; es especialmente en su estructura urbana donde se puede apreciar un carácter sencillo, claro y lógico de organización de cada uno de los sistemas físicos y sociales que lo componen, que da como resultado soluciones que responden a los diferentes problemas que surgen en la dinámica de desarrollo de las actividades normales del barrio: perfiles viales generosos en cuanto a sus dimensiones y una trama vehicular muy clara, lo que permite una buena conexión y accesibilidad al barrio, entre otros aspectos de los que se dará cuenta en el desarrollo de la investigación.

El problema de la movilidad en la ciudad de Bucaramanga se incrementa, cada vez más, debido a la falta de planificación y al incremento poblacional, lo que genera aumentos de los índices de densidad, entre otros conflictos, en el espacio urbano. Como solución de este problema, algunas entidades estatales adelantan un proyecto llamado TRONCAL NORTE - SUR, el cual surge como alternativa para conectar vialmente el centro con el sur de la ciudad; uno de los elementos que lo componen se denomina VIADUCTO DE LA CARRERA NOVENA, el cual comunicará el centro de la ciudad con la Ciudadela Real de Minas, en donde uno de los tramos que se realizarán para generar la conexión por medio del viaducto es el tramo número 4 que se denomina adecuación de la Carrera 2W; esta vía corresponde al eje central y de mayor actividad del barrio Mutis, por ello se proyecta una ampliación del perfil vial, hecho que obliga a la demolición de varios predios, equipamientos, dotaciones y espacio público de gran importancia para el sector. Este tipo de intervenciones genera gran cantidad de impactos desde el punto de vista social, ambiental, económico y urbano. En este orden de ideas, para tales efectos es importante realizar un análisis y diagnóstico de la composición actual del eje principal del barrio, es decir, la Carrera 2W y de los impactos que traerá el proyecto vial al sector y a sus habitantes.

\section{JUSTIFICACIÓN}

A partir de un interés especial por la cátedra "Análisis y proyecto urbano ambiental”3 durante la carrera y de la constante curiosidad por investigar en nuestro entorno inmediato la corroboración y aplicación a la realidad de algunos de los conceptos expuestos por el

3 Asignatura impartida en la Facultad de Arquitectura por el docente Arq. Pedro Antonio Gómez Bejarano 
filósofo francés Henry Lefébvre en sus más importantes obras sobre urbanismo entre ellas su obra "El derecho a la ciudad II, Espacio y Política" más específicamente con respecto a su ideología, "La ciudad es la proyección de la sociedad global sobre el terreno" descripción y percepción de lo que es una ciudad, cómo se transforma como una expresión social de quienes la habitan y los distintos aspectos involucrados en dicha transformación, se eligió como referente para la investigación uno de los barrios más tradicionales $y$, a su vez, mejor conformados del municipio de Bucaramanga, el barrio Mutis ubicado al Noroccidente de la ciudad, fundado hace 44 años, diseñado y construido en sus orígenes basado en principios urbanos y arquitectónicos como el modelo teórico propuesto en el estudio de Normas Mínimas de Urbanización, Servicios Públicos y Servicios Comunitarios de 1972, el cual, a pesar de las transformaciones propias y naturales de cualquier espacio habitado por humanos, es considerado hasta hoy un ejemplo de organización y buena respuesta al problema de la vivienda, pues tiene un carácter sencillo, claro y lógico de organización de cada uno de los sistemas físicos y sociales que lo componen, y deja como resultado soluciones que responden a los diferentes problemas de cada una de las actividades normales que tiene un barrio. Debido a la cantidad de información recopilada y para delimitar un poco más la investigación, el foco principal de atención se centró en la vía principal del barrio, la Carrera 2W, que ha sido el sector de mayor transformación y actividad del barrio.

Al tener en cuenta que la investigación es el único medio para la toma de decisiones frente a cualquier problemática y además conscientes de la falta de interés y compromiso institucional por efectuar investigaciones y estudios previos que evalúen los impactos posteriores generados en el desarrollo de cualquier proyecto urbano, se decidió ampliar el alcance de la investigación, para producir un conjunto de estrategias para contrarrestar los impactos ocasionados con la realización del Viaducto de la Novena y así proponer soluciones alternativas para la conservación y el mejoramiento de la calidad de vida de los habitantes del área de estudio.

\section{OBJETIVOS}

\section{General}

Analizar la configuración del barrio Mutis de Bucaramanga y determinar la composición, estructura urbana y transformación del eje de mayor actividad del barrio, la Carrera 2W.

\section{Específicos}

- Recopilar información que permita reconocer (desde lo funcional y espacial) la configuración del barrio Mutis, su entorno inmediato y su eje de mayor actividad.

- Analizar y diagnosticar la configuración urbana del área de estudio y de la Carrera 2W.

- Determinar la incidencia del proyecto vial (tramo 4 -troncal N S viaducto Carrera $9^{\circ}$ ) en la transformación de la estructura urbana del barrio y su zona de mayor transformación.

- Generar estrategias que puedan ser útiles para mitigar los efectos producidos por el proyecto vial sobre la zona de influencia a modo de recomendaciones.

4 LEFEBVRE, Henry. Op. Cit., p. 10 


\section{MARCO TEÓRICO}

Numerosos han sido los autores que desde distintas disciplinas como la sociología, la filosofía, la antropología y la arquitectura han realizado análisis de la vida urbana desde sus distintas dimensiones y aportado nuevas teorías y conceptos para el planeamiento de las grandes ciudades. Dentro de estos aportes es preciso tener en cuenta las consideraciones del filósofo francés Henri Lefevbre, quien realiza una importante reflexión crítica de la problemática urbana, al tomar como universo de análisis a la ciudad de París, referente de sus más importantes obras, entre las que se encuentran El derecho a la ciudad (1968), La revolución urbana (1970), El derecho a la ciudad II: Espacio y política (1972) y La producción del espacio (1974). A partir de sus observaciones y por medio del análisis de las formas espaciales, la política del espacio y la reproducción capitalista en la ciudad, aborda la problemática urbana de una forma crítica, desarrolla una teoría que permite entender cómo se configura la realidad de los espacios urbanos y la forma en que la ciudad llega a convertirse en "La proyección de la sociedad global sobre el terreno"5, incluye componentes espaciales, sociales y políticos, los cuales se complementan y relacionan entre sí.

Es así que la lectura y análisis de la obra de Lefebvre, llega a convertirse en el principal referente de estudio, se toma su teoría como guía para el desarrollo de esta investigación, al ser ésta útil para contrastar las categorías allí planteadas con la realidad que se percibe en la cotidianidad del barrio Mutis y su entorno inmediato, principalmente su zona de mayor actividad: la carrera $2 \mathrm{~W}$. Finalmente, se recopila la información necesaria para realizar un diagnóstico completo del área de estudio, generar conclusiones y proponer recomendaciones.

\section{MARCO CONCEPTUAL}

Para apoyar algunas conclusiones de esta investigación y proponer las respectivas recomendaciones con respecto al tema del espacio público, se tomaron algunos conceptos teórico - técnicos consignados en la Guía práctica de la movilidad peatonal realizada por el Instituto de Desarrollo Urbano de Bogotá (IDU), que busca fortalecer la planificación, los estudios, diseños y ejecución de los proyectos, con el propósito de garantizar que se incluyan los siguientes principios y categorías para el manejo adecuado de la movilidad de todo tipo de usuarios del espacio público.

Los siguientes lineamientos de accesibilidad y movilidad peatonal son, a su vez, una adaptación de los siete principios del diseño universal recogidos en la versión 2.0 del I de abril de 1997, del Centro para el Diseño Universal (NC Stage University, The Center for Universal Desing, an initiative of the College of Desing) aplicados a la movilidad peatonal.

Accesibilidad en la movilidad peatonal: La accesibilidad se puede entender como la facilidad en el desplazamiento de los peatones para acceder o interactuar en un espacio público. En términos prácticos implica que los peatones logren llegar, ingresar, usar y salir, de los espacios de origen o destino referidos a intereses particulares ${ }^{6}$.

Ley de Universalidad: El diseño universal aplicado a la movilidad peatonal tiene como objetivo principal simplificar la vida del peatón. El entorno construido debe contemplar la

\footnotetext{
Ibídem.

6 Guía Práctica de la movilidad peatonal urbana, Instituto de Desarrollo Urbano de Bogotá IDU. Bogotá, 2005. p. I5
} 
posibilidad de ser utilizado por el mayor número de peatones como sea posible a un costo mínimo y beneficiar a todas las personas de diferentes edades y capacidades. El diseño universal debe ayudar a todas las personas con movilidad reducida ofreciéndoles un margen de seguridad, de allí que se trate de un conjunto de elementos cuya disposición adecuada hace que el entorno sea accesible y utilizable.

Los siete principios del diseño ${ }^{7}$

\section{Uso equitativo}

El diseño debe ser útil y conveniente para todas las personas de distintas discapacidades.

- El espacio debe ser utilizado por todos en igualdad de condiciones, o de lo contrario en condiciones equivalentes.

- El espacio debe evitar segregar o estigmatizar a cualquier usuario

- Los elementos o áreas reservadas para el peatón con movilidad reducida deben estar disponibles para todos los usuarios.

\section{Flexibilidad en el uso}

El diseño debe adaptarse a una amplia variedad de preferencias y capacidades individuales.

- El espacio debe ofrecer opciones para su movilidad.

- En lo posible debe dar la posibilidad de ser usado por diestros y zurdos

- Se debe facilitar la exactitud y la precisión del usuario.

- Se debe brindar adaptabilidad al ritmo del usuario.

\section{Uso sencillo e intuitivo}

El diseño debe ser fácil de entender, independientemente de la experiencia, los conocimientos, las habilidades lingüísticas o nivel de concentración del usuario.

- Se debe eliminar las complejidades innecesarias.

- Los espacios deben estar organizados de tal forma que el itinerario del peatón sea lógico y secuencial con su recorrido, es decir; poder llegar, ingresar, usar y salir.

- La señalización debe proporcionar comentarios eficientes durante y después de los recorridos.

\section{Información perceptible}

El diseño debe comunicar la información necesaria de manera eficaz, sin importar las condiciones ambientales o las capacidades sensoriales de los usuarios; lo que se traduce en:

- Usar los medios gráficos, táctiles, verbales para informar al usuario de sus derechos y deberes.

- Proporcionar un contraste entre la información esencial y su entorno.

$7 \quad$ Ibíd., pp. 15-19 
- Optimizar la "legibilidad" de la información esencial.

- Ofrecer compatibilidad con diversas técnicas o dispositivos usados por los peatones que tienen limitaciones sensoriales.

\section{Tolerancia al error}

El diseño debe reducir al mínimo los riesgos y las consecuencias adversas de acciones accidentales o realizadas sin intención.

- Los elementos del espacio se deben organizar de tal forma que minimice los riesgos y los errores.

- Informar o advertir sobre la posibilidad de riesgo o error.

\section{Esfuerzo físico reducido}

Los elementos diseñados en el contexto urbano deben contemplar el uso eficiente y confortable de los usuarios con un mínimo de fatiga.

- Debe permitirse que el usuario conserve una posición corporal neutral.

- Se debe procurar que los usuarios utilicen su fuerza razonablemente al realizar un itinerario.

- Los recorridos en lo posible deben evitar acciones repetitivas.

\section{Tamaño y espacio para acercarse y usar}

Se debe proporcionar un tamaño y un espacio adecuados para acercarse, alcanzar, manipular y usar, sin que importe el tamaño corporal del usuario, su postura o su movilidad.

- Se debe proporcionar una línea de visión clara hacia los elementos importantes para cualquier usuario, esté sentado o de pie.

- Los elementos deben ser alcanzados por cualquier usuario, esté sentado o de pie.

- Se deben ajustar las variaciones al tamaño de la mano y el puño.

- Se debe proporcionar un espacio adecuado para el uso de dispositivos de asistencia o ayuda personal.

\section{MARCO LEGAL}

Dentro del marco jurídico de esta investigación, se tomaron como referentes normativos algunas leyes, normas y decretos contenidos en el Plan de Ordenamiento Territorial (POT) del municipio de Bucaramanga, el Manual del Espacio Público del municipio de Bucaramanga y la Guía práctica de la movilidad peatonal. A continuación se exponen cada uno de ellos por condicionar el desarrollo de esta investigación 


\section{Cuadro I. Normativa que condiciona el proyecto}

\begin{tabular}{|c|c|}
\hline NORMATIVA & CONTENIDO \\
\hline $\begin{array}{l}\text { Ministerio de Transporte de la República } \\
\text { de Colombia. } \\
\text { Decreto número } 1660 \text { del } 16 \text { de Junio } \\
\text { de } 2003 \text {. } \\
\text { Por el cual se reglamenta la accesibilidad } \\
\text { a los modos de transporte de la población } \\
\text { en general y, en especial, de las personas } \\
\text { con discapacidad. }\end{array}$ & $\begin{array}{l}\text { En el artículo primero de este decreto se establece el objeto de la normativa, } \\
\text { la cual consiste en fijar la normatividad general que garantice gradualmente la } \\
\text { accesibilidad a los modos de transporte y la movilización en ellos de la población } \\
\text { en general y en especial, de todas aquellas personas con discapacidad. } \\
\text { En el capítulo dos, se establecen las definiciones de las categorías que deben } \\
\text { tenerse en cuenta en un proyecto de movilidad, entre ellas se encuentran la } \\
\text { accesibilidad, las barreras físicas, discapacidad, movilidad, señalización mixta y } \\
\text { transporte mixto, entre otras. } \\
\text { El capítulo III se menciona la necesidad de capacitar al personal de las empresas } \\
\text { de transporte y demás gremios y grupos involucrados con las actividades del } \\
\text { transporte. } \\
\text { En el capítulo IV se demarcan las zonas especiales de estacionamiento y } \\
\text { parqueo; las condiciones generales y especiales de la accesibilidad son tratadas } \\
\text { en el capítulo V, en tanto que en el VI se establecen las disposiciones sobre } \\
\text { accesibilidad en el transporte público, de alto interés para el desarrollo de esta } \\
\text { investigación. En los siguientes capittulos se abordan disposiciones para tener en } \\
\text { cuenta cuando se trate de transporte marítimo, fluvial, ferroviario y transporte } \\
\text { aéreo, los cuales no fueron tenidos en cuenta en la investigación por no estar } \\
\text { relacionados con el objetivo de la misma. } \\
\text { El capituloXII está relacionado con las sanciones que acarrean el incumplimiento } \\
\text { de las disposiciones señaladas en el decreto, una de las cuales es una multa } \\
\text { para los proyectos que no contemplen en sus diseños la disposición de sitios } \\
\text { de parqueo. }\end{array}$ \\
\hline $\begin{array}{l}\text { Por el cual se reglamenta parcialmente } \\
\text { la Ley } 361 \text { del } 7 \text { de Febrero de } 1997 . \\
\text { (Por la cual se establecen mecanismos } \\
\text { de integración social de las personas con } \\
\text { limitación y se dictan otras disposiciones) }\end{array}$ & $\begin{array}{l}\text { ART. I. ÁMBITO DE APLICACIÓN. Las disposiciones contenidas en el presente } \\
\text { decreto serán aplicables para: } \\
\text { a) El diseño, construcción, ampliación, modificación y en general, cualquier } \\
\text { intervención y/o ocupación de vías públicas, mobiliario urbano y demás } \\
\text { espacios de uso público. } \\
\text { b) El diseño y ejecución de obras de construcción, ampliación, adecuación y y } \\
\text { modificación de edificios, establecimientos e instalaciones de propiedad pública } \\
\text { o privada, abiertos y de uso al público. } \\
\text { ART, 2. DEFINICIONES. Para efectos de la adecuada comprensión y aplicación } \\
\text { del presente decreto, se establecen las siguientes definiciones: } \\
\text { I. Accesibilidad: Condición que permite, en cualquier espacio o ambiente } \\
\text { ya sea interior o exterior, el fácil y seguro desplazamiento de la población } \\
\text { en general y el uso en forma confiable, eficiente y autónoma de los servicios } \\
\text { instalados en esos ambientes. } \\
\text { 2. Barreras físicas: Son todas aquellas trabas, irregularidades y obstáculos físicos } \\
\text { que limitan o impiden la libertad o movimiento de las personas. } \\
\text { 3. Barreras arquitectónicas: Son los impedimentos al libre desplazamiento de } \\
\text { las personas, que se presentan al interior de las edificaciones. } \\
\text { 4. Movilidad reducida: Es la restricción para desplazarse que presentan algunas } \\
\text { personas debido a una discapacidad o que sin ser discapacitadas presentan algún } \\
\text { tipo de limitación en su capacidad de relacionarse con el entorno al tener que } \\
\text { acceder a un espacio o moverse dentro del mismo, salvar desniveles, alcanzar } \\
\text { objetos situados en alturas normales. } \\
\text { 5. Edificio abierto al público: Inmueble de propiedad pública o privada de uso } \\
\text { institucional, comercial o de servicios donde se brinda atención al público. }\end{array}$ \\
\hline $\begin{array}{l}\text { Decreto } 078 \text { del I I de Junio de } 2008 \text {. Por el } \\
\text { cual se compilan los Acuerdos } 034 \text { de } 2000 \text {, } \\
018 \text { de } 2002,046 \text { de } 2003 \text { y } 046 \text { de } 2007 \\
\text { que conforman el Plan de Ordenamiento } \\
\text { Territorial del Municipio de Bucaramanga. }\end{array}$ & $\begin{array}{l}\text { Se consideran en esta investigación todos los lineamientos establecidos en el } \\
\text { Plan de Ordenamiento Territorial del municipio de Bucaramanga. }\end{array}$ \\
\hline
\end{tabular}

Fuente: Elaborado por la autora con base en información consultada 


\section{DISEÑO METODOLÓGICO}

Es preciso señalar en este apartado que la investigación ha sido dividida en dos etapas, cada de una de las cuales está relacionada con una categoría de análisis particular; corresponde entonces la primera etapa al estudio del área de influencia, en tanto la segunda, al diagnóstico del área de intervención. A continuación se dará cuenta de la metodología empleada durante el proceso de investigación, cuyas fichas de recolección que sirvieron de base para el desarrollo de la misma, fueron extraídas de la investigación Viejas estructuras nuevas oportunidades. Escenarios urbanos Bucaramanga, USTA, 2007².

Para realizar el análisis de las dos etapas se emplearon las siguientes categorías:

- Descripción de la situación actual: Acercamiento a la imagen actual del barrio Mutis, a partir del análisis de las variables como el sistema natural y el sistema construido?.

- Explicación: Dentro de esta etapa se realiza el análisis de la información, para entender las causas de los fenómenos hallados en el trabajo de campo ${ }^{10}$.

- Evaluación de la situación actual: A partir de la confrontación de la situación actual con la imagen deseada, se emiten conceptos y ponderaciones específicas de cada situación, de tal manera que permita jerarquizar alternativas de posibles soluciones en las etapas siguientes".

Los factores descritos en el diseño metodológico se explican a continuación por medio de fases:

Cuadro 2. Descripción de la metodología

\begin{tabular}{|c|l|c|}
\hline FASE & \multicolumn{1}{|c|}{ DESCRIPCIÓN } & DURACIÓN \\
\hline I & $\begin{array}{l}\text { Recolección de información sobre las áreas de análisis (planos, normativa, } \\
\text { documentación), organización y elaboración de documentos necesarios para } \\
\text { iniciar la segunda fase -ficha Matriz de análisis- }\end{array}$ & 3 Semanas \\
\hline 2 & $\begin{array}{l}\text { Trabajo de campo: Reconocimiento de áreas de análisis, corroboración de la } \\
\text { información previamente ubicada (toma de medidas marcación y ubicación en } \\
\text { planos) toma de fotografías, selección de muestra de manzanas a aplicar la ficha } \\
\text { de análisis y consignar la información de las fichas. }\end{array}$ & 6 Semanas \\
\hline 3 & $\begin{array}{l}\text { Selección análisis y consignación de información recogida durante la etapa previa: } \\
\text { Trabajo de Campo }\end{array}$ & 8 semanas \\
\hline
\end{tabular}

Fuente: Elaborado por la autora

\section{RECOLECCIÓN Y ANÁLISIS PREVIO DE LA INFORMACIÓN}

La ubicación planimétrica de las áreas de análisis, se realizaron basados en imágenes de fuentes como Google Earth, Plan de Ordenamiento Territorial POT e Instituto Geográfico Agustín Codazzi, IGAC, las cuales permitieron la localización, delimitación y análisis de las áreas de estudio.

8 RUEDA GÓMEZ, Néstor; GÓMEZ SUÁREZ, José Alejandro. Viejas estructuras nuevas oportunidades. Escenarios Urbanos. Bucaramanga, Universidad Santo Tomás, 2007

$9 \quad$ Ibíd., p.77

10 Ibídem.

II lbídem. 
En esta etapa fue necesario recolectar información normativa (POT y el programa Arcview) e institucional (área metropolitana de Bucaramanga AMB, Universidad Santo Tomás e Instituto de Crédito Territorial ICT), así mismo se tomaron referencias de autores y teorías referentes al tema de investigación entre los cuales se analizó la formación sobre el origen y configuración del barrio Mutis desarrollada por el Historiador Néstor José Rueda Gómez, docente de la Facultad de arquitectura de la Universidad Santo Tomás, seccional Bucaramanga y el modelo teórico propuesto en el estudio de Normas Mínimas de Urbanización, Servicios Públicos y Servicios Comunitarios de 1972 realizado por el arquitecto Alberto Saldarriaga Roa, especialista en vivienda y planeamiento urbano.

Posterior a la etapa de recolección de la información, se realizó el análisis de la información recopilada, lo cual permitió establecer los siguientes parámetros de investigación y de recolección de información adicional, para cumplir con los objetivos de la investigación.

\section{MATRIZ DE ANÁLISIS}

La matriz de análisis se realizó durante la etapa Il del proceso de investigación, consistente en la elaboración de dos fichas -formato A y B- con espacios en blanco para consignar información que permitió la caracterización de predios y del espacio público. Para su elaboración se aplicó la metodología planteada en la investigación Viejas estructuras nuevas oportunidades. Escenarios urbanos Bucaramanga, USTA, 2007, adaptándola a los requerimientos propios del sector de análisis. Con el fin de obtener mayor comprensión sobre tan importante herramienta para la elaboración del diagnóstico de la etapa ll se realiza una descripción general de las principales categorías de análisis para cada uno de los formatos: A y B (ver Imagen I y 2).

\section{Ficha de análisis formato A}

- Información general de la ficha de análisis: información que permite identificar el objetivo de las fichas como autor, institución, fecha y formato, en este caso A.

- Ubicación y localización de las manzanas: esta información se relaciona con la ubicación de las manzanas del barrio Mutis con respeto al norte y una numeración de I a I6, además de la dirección y el costado de la misma.

- Localización gráfica de las áreas de análisis: este campo permite la localización de las áreas desde diferentes escalas, con el fin de facilitar la ubicación y comprensión sobre los pedios y manzanas.

- Identificación y datos generales: dentro de este campo se consignaron datos adicionales, como por ejemplo información gráfica sobre perfiles viales importantes, con el fin de obtener una mayor comprensión de la configuración de las áreas de análisis, además de las imágenes de las manzanas analizadas en cada ficha.

- Categorías de análisis generales y específica sobre los usos del suelo:

- Residencial: vivienda, vivienda/comercio y vivienda/industria

- Comercial: diario, general, especial, centro comercial, hospedaje, motel, restaurante, banco, oficina y parqueadero. 
- Industrial

- Dotacional: servicios urbanos, culto, educación y salud

- Recreativo

- Vacíos: lote, parqueadero, otro

- Observaciones

- Cobertura/ centralidad: Metropolitana, urbana, zonal y local

- Impacto: bajo, medio y alto

- Número del predio analizado

- Nombre del predio analizado

- Dirección del predio analizado

- Cara del predio analizado

- $\quad N^{\circ}$ de las fotos sobre el predio tomadas durante el registro fotográfico

- Totales: información que compila los datos del análisis, lo que facilita la comprensión y justificación de cada una de las categorías empleadas en el desarrollo del diagnóstico (Ver Imagen I.)

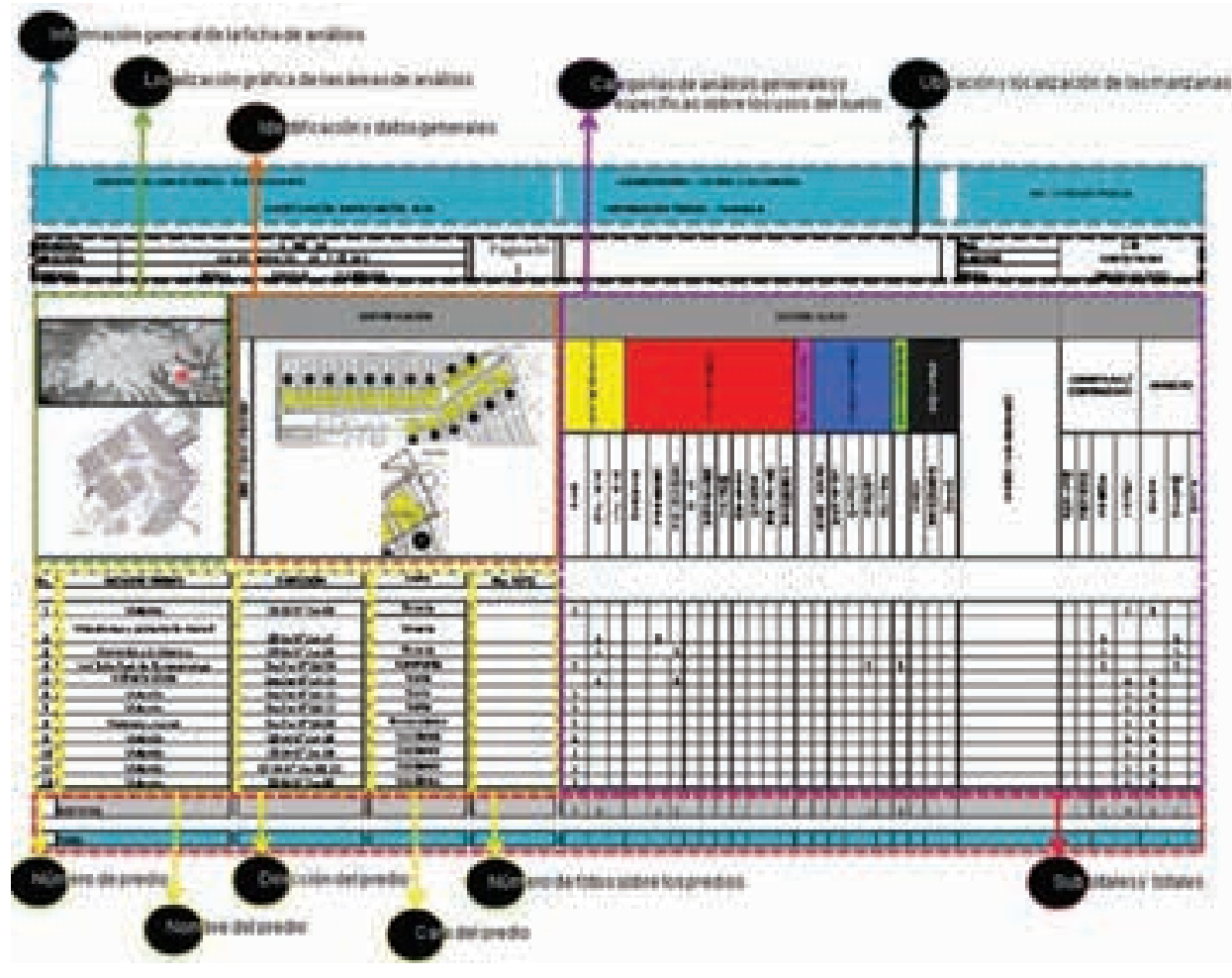

magen I. Ficha de análisis Formato A. Fuente: Elaborado por la autora con base en el proceso realizado en el trabajo de campo 


\section{Ficha de análisis formato B}

- Información general de la ficha de análisis: información que permite identificar el objetivo de las fichas como autor, institución, fecha y formato en este caso B.

- Ubicación y localización de las manzanas: Allí se consignó la ubicación de las manzanas del barrio Mutis con respeto al norte y una numeración de I a 16 , además de la dirección y el costado de la misma.

- Localización gráfica de las áreas de análisis: este campo permite la localización de las áreas desde diferentes escalas, con el fin de facilitar la ubicación y comprensión sobre los pedios y manzanas.

- Identificación y datos generales: dentro de este campo se consignaron datos adicionales de diferentes aspectos, por lo general, se consignó información gráfica sobre perfiles viales importantes con el fin de una mayor comprensión de la configuración de las áreas de análisis, además de las imágenes de las manzanas analizadas en cada ficha.

- Categorías de análisis sobre el Tejido Edilicio:

- $\quad N^{\circ}$ de pisos: I, 2, 3-5, 5-10 y más de 10

- Voladizos

- Puertas: $\mathrm{N}^{\circ}$, peatonal y vehicular

- Frente: zona dura, zona verde, árbol y antejardín

- Estado/calidad: bueno, regular y malo

- Edad predial aproximada (años): 00-10, 10-20, 20-50, 50-100, más de 100

- Valoración patrimonial: Urbano, arquitectónico, artístico y otro

- Conflictos: usos, acceso, estacionamiento, paramento, voladizo y ambiental

- Número del predio analizado

- Nombre del predio analizado

- Dirección del predio analizado

- Cara del predio analizado

- $\mathrm{N}^{\circ}$ de las fotos sobre el predio tomadas durante el registro fotográfico

- Subtotal y total: información que copila los datos del análisis, lo que facilita la comprensión y justificación de cada una de las categorías analizadas para el desarrollo del diagnóstico (Ver Imagen 2.)

La metodología empleada en la elaboración de las fichas se dividió en 2 etapas:

I. Selección de manzanas: La cual consistió en seleccionar parte de las manzanas de los predios más cercanos al área de intervención: la Carrera $2 \mathrm{~W}$, por ser los directamente afectados debido a los cambios y transformaciones de la misma; las manzanas fueron numeradas de I a 16, desde el costado oriental de la vía hasta el costado occidental de la misma. 


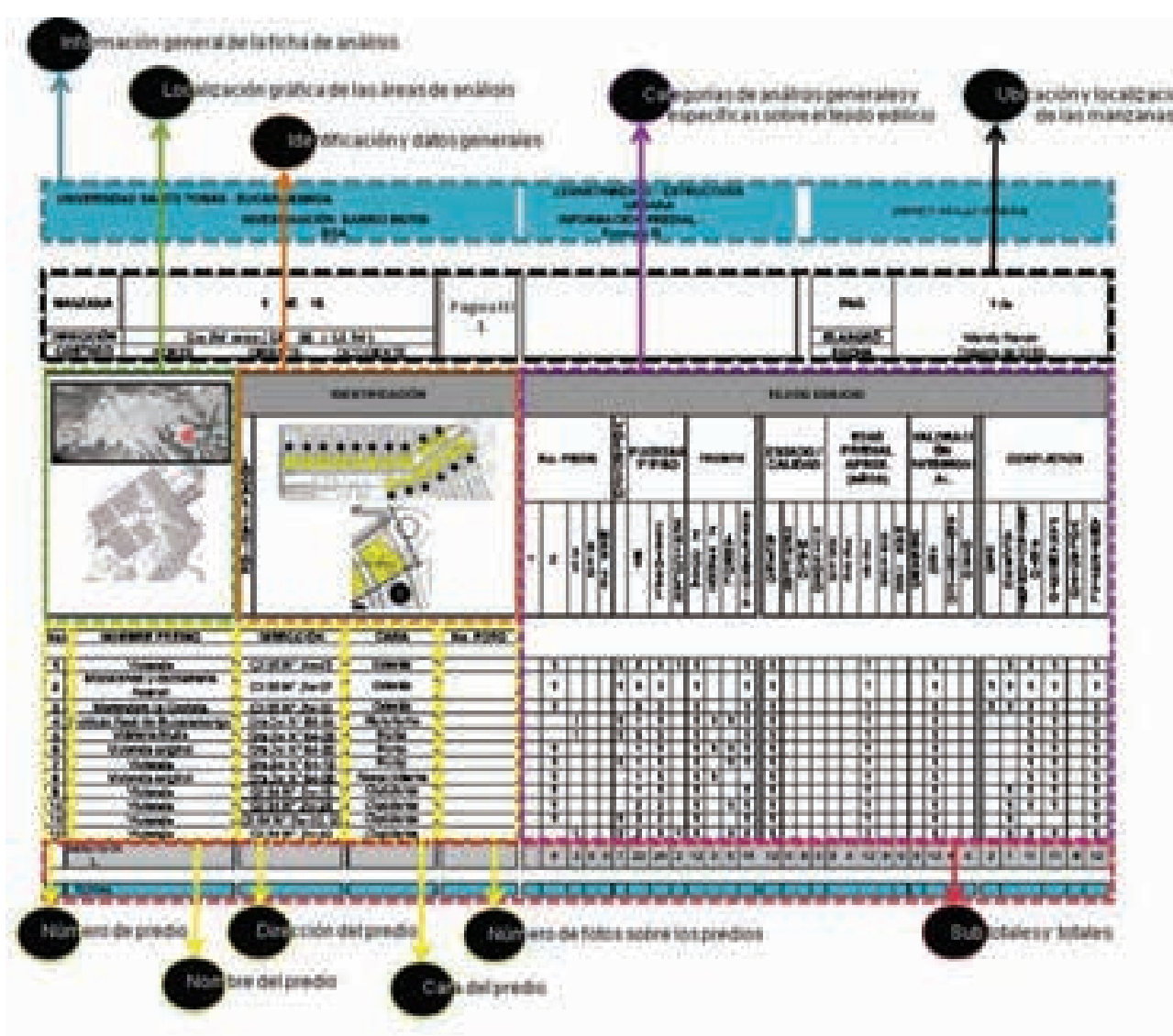

Imagen 2. Ficha de análisis Formato B. Fuente: Elaborado por la autora con base en el proceso realizado en el trabajo de campo

2. Selección de predios: Se escogieron predios paralelos y perpendiculares a la vía dentro de la selección anterior de las manzanas, la recolección de la información de los predios se hizo en forma ordenada en el sentido contrario a las manecillas del reloj, con el fin de evitar confusiones debido a la gran cantidad de información; en este mismo orden se realizó el registro fotográfico de cada predio; en total se analizaron 177 predios dentro de las 16 manzanas, de la siguiente manera:

\begin{tabular}{|c|c|}
\hline Manzana & Número de predios \\
\hline 1 & 12 \\
\hline 2 & 14 \\
\hline 3 & 9 \\
\hline 4 & 10 \\
\hline 5 & 8 \\
\hline 6 & 3 \\
\hline 7 & 12 \\
\hline 8 & 11 \\
\hline 9 & 14 \\
\hline 10 & 12 \\
\hline 11 & 12 \\
\hline 12 & 12 \\
\hline 13 & 12 \\
\hline 14 & 12 \\
\hline 15 & 12 \\
\hline 16 & 12 \\
\hline
\end{tabular}


Para efectos de mayor comprensión del método de selección y consignación de la información de los predios y las manzanas se utiliza la siguiente imagen:

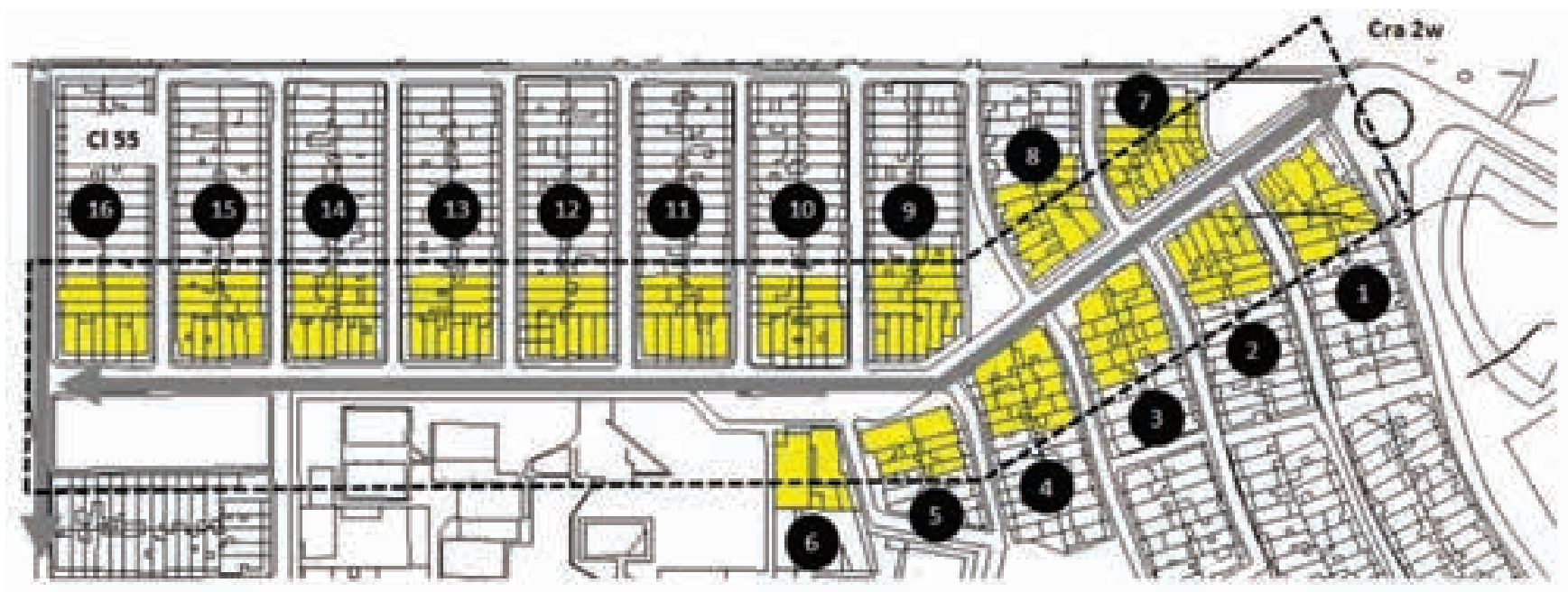

Imagen 3. Selección de manzanas y predios de análisis. Fuente: Elaborado por la autora con base en el proceso realizado en el trabajo de campo
Vale la pena resaltar que el registro de la información de las fichas de análisis fue realizado a mano gradualmente, luego de efectuar cada una de las visitas de campo, para ello se requirió gran inversión de tiempo y observación en detalle de lo que ocurría en el sector. Se considera esta actividad como una de las más importantes de la investigación.

\section{TRABAJO DE CAMPO}

Para el desarrollo de esta etapa fue necesario disponer de seis semanas con tres visitas semanales, para un total de 18 visitas, tiempo durante el cual se recopiló y organizó la información en las respectivas fichas de análisis. Otras actividades realizadas dentro del trabajo de campo fueron:

- Toma de medidas, marcación y ubicación del contexto físico sobre planos

- Registro fotográfico

- Observación

- Entrevistas y encuestas

Toma de medidas, marcación y ubicación del contexto físico sobre planos: Estas actividades fueron realizadas para elaborar el levantamiento de alturas y demás componentes del barrio Mutis, para luego ser digitalizado con el fin de permitir mayor observación y análisis del barrio y su área de mayor actividad.

Registro fotográfico: Para consignar la totalidad de la información requerida en las fichas de análisis fue necesario realizar un registro fotográfico con el objetivo de llevar un control de cada predio analizado y usar dicha documentación para realizar análisis de cada uno de ellos y comparar las imágenes y la información consignada en las fichas.

Análisis de flujos y actividades: La observación es uno de los aspectos más importantes para realizar un diagnóstico y principal habilidad de un profesional de la arquitectura, por 
esta razón por medio de ella se analizaron los flujos y actividades peatonales y vehiculares de las áreas de estudio.

Entrevistas y encuestas: Se realizaron entrevistas y encuestas con el fin de recolectar información, aclarar dudas y corroborar teorías estudiadas durante el proceso de análisis del trabajo de investigación. Las personas a las cuales se entrevistó fueron el historiador Néstor José Rueda Gómez (Docente de la facultad de Arquitectura de la Universidad Santo Tomás, seccional Bucaramanga), representantes de la administración del Parque Recrear del Barrio Mutis, población del Barrio Mutis (niños y adultos), Ingeniero Javier Mantilla Gaitán y el Arquitecto Wálter Miguel Díaz Quintero representantes del área metropolitana de Bucaramanga (ver Cuadro 4).

Cuadro 4. Entrevistas y encuestas

\begin{tabular}{|l|l|}
\multicolumn{1}{|c|}{ ENTREVISTADO } & \multicolumn{1}{c|}{ APOYO } \\
\hline Historiador Néstor José Rueda Gómez & Explicación de origen y configuración del barrio Mutis. \\
\hline $\begin{array}{l}\text { Representantes de la administración del Parque } \\
\text { Recrear del barrio Mutis }\end{array}$ & $\begin{array}{l}\text { Funcionamiento, actividades y precios de los servicios que presta } \\
\text { el parque a la comunidad. }\end{array}$ \\
\hline Población del barrio Mutis (niños y adultos) & $\begin{array}{l}\text { Opiniones sobre la configuración, actividades del barrio y aspectos } \\
\text { a mejorar del mismo. }\end{array}$ \\
\hline Ingeniero Javier Mantilla Gaitán & $\begin{array}{l}\text { Exposición de la configuración y solución de dudas sobre el } \\
\text { proyecto: Troncal Metropolitana Norte - Sur: tramo 4. }\end{array}$ \\
\hline Arquitecto Wálter Miguel Díaz Quintero & $\begin{array}{l}\text { Explicación general del proyecto vial y suministro de información } \\
\text { sobre el mismo. }\end{array}$ \\
\hline
\end{tabular}

Fuente: Elaborado por la autora con base en el proceso realizado en el trabajo de campo

\section{RESULTADOS DE LA INVESTIGACIÓN'2 \\ LOCALIZACIÓN Y DELIMITACIÓN DE LAS ÁREAS DE ANÁLISIS}

Localización: El área de estudio se encuentra ubicada en la ciudad de Bucaramanga, Santander, según el Plan de Ordenamiento Territorial de Bucaramanga POT, el área de intervención hace parte de la comuna I3, dentro del Barrio Mutis en la carrera $2 \mathrm{~W}$ entre las calles 56 y 65 , lo que corresponde a la vía y los predios más cercanos a ella.

\section{DELIMITACIÓN DE LAS ÁREAS DE ANÁLISIS}

Área de Referencia: El proyecto objeto de análisis se encuadra dentro del ámbito espacial de la Meseta. Su localización estratégica sobre el extremo del Llano de los Ordoñez al sur-occidente, le otorga un valor añadido como enclave singular al producir un elemento de extensión urbana entre la ciudad consolidada y los nuevos desarrollos. Hoy su papel es más preponderante al conectarse los filamentos urbanos de escarpa a través de modernas infraestructuras. La hacienda Bellavista fue el epicentro de la actuación del proyecto Mutis del ICT, pero, una vez trasladado el Aeropuerto Gómez Niño, a Palonegro, sus suelos fueron capitalizados para el proyecto Ciudadela Real de Minas, en este sentido el análisis cubre este ámbito de influencia.

I2 En el presente artículo sólo se dará cuenta de la Etapa I de la investigación correspondiente a la Configuración del área de influencia, pues la etapa II Diagnóstico del área de intervención, se publicará en una próxima entrega de la Revista. 
Imagen 4. Área de referencia. Fuente: Elaborado por la autora con base en planimetría del Plan de Ordenamiento Territorial y fotografia aérea IGAC

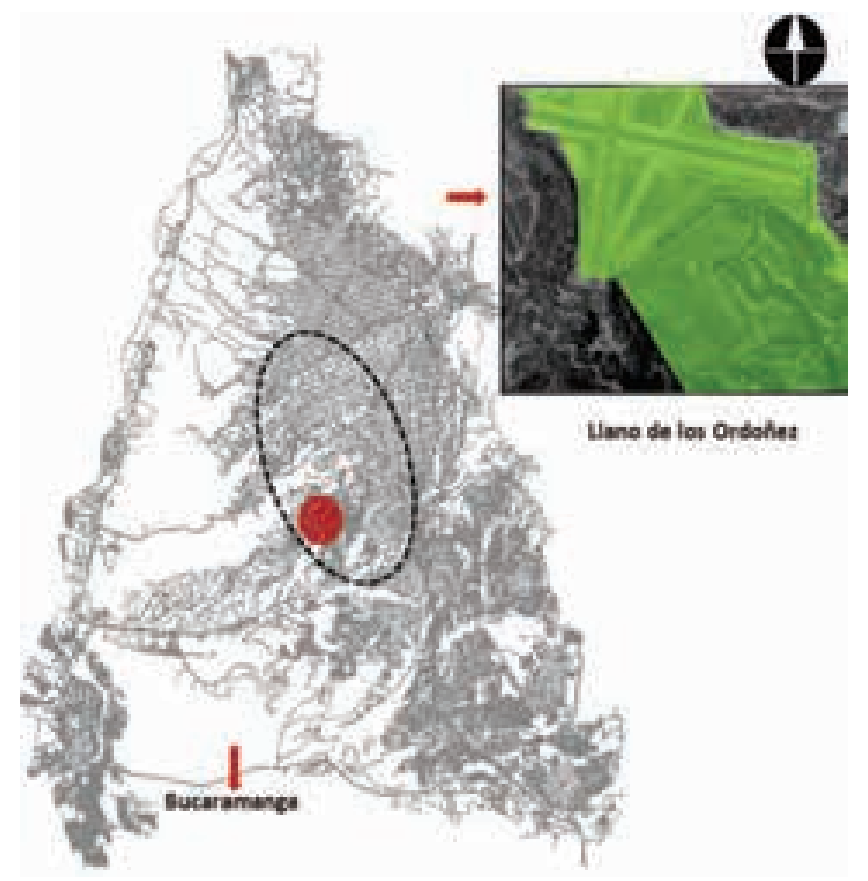

Área de Influencia: Esta área se encuentra conformada por el Barrio Mutis, ya que se constituye como el área inmediata y zona directamente influenciada por el sector que se va a estudiar.

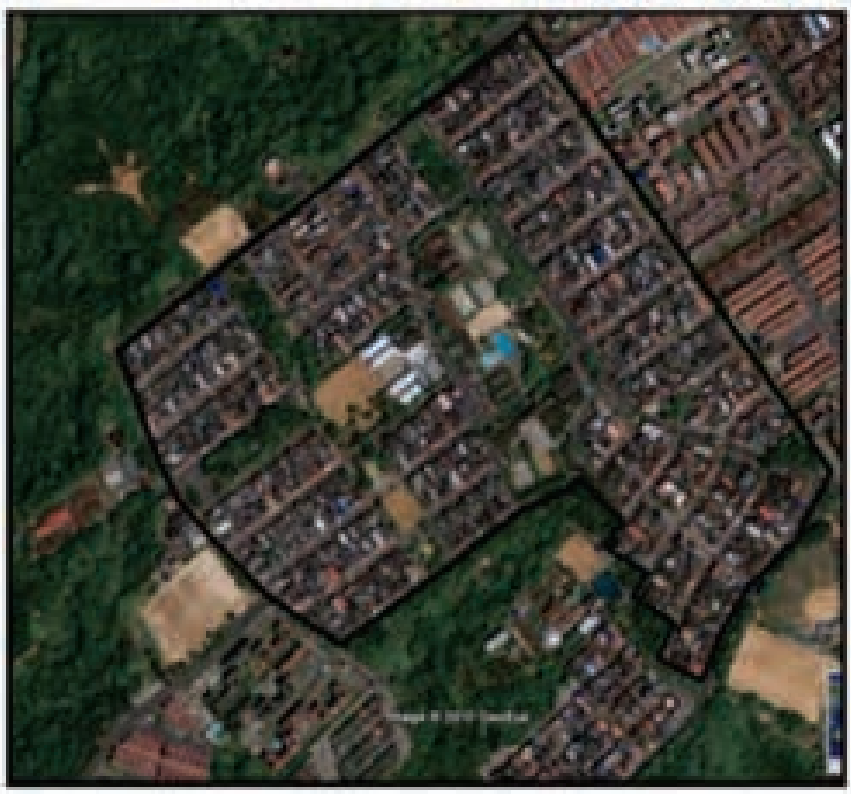

Imagen 5. Barrio Mutis Área de influencia. Fuente: Fotografia satelital Google Earth

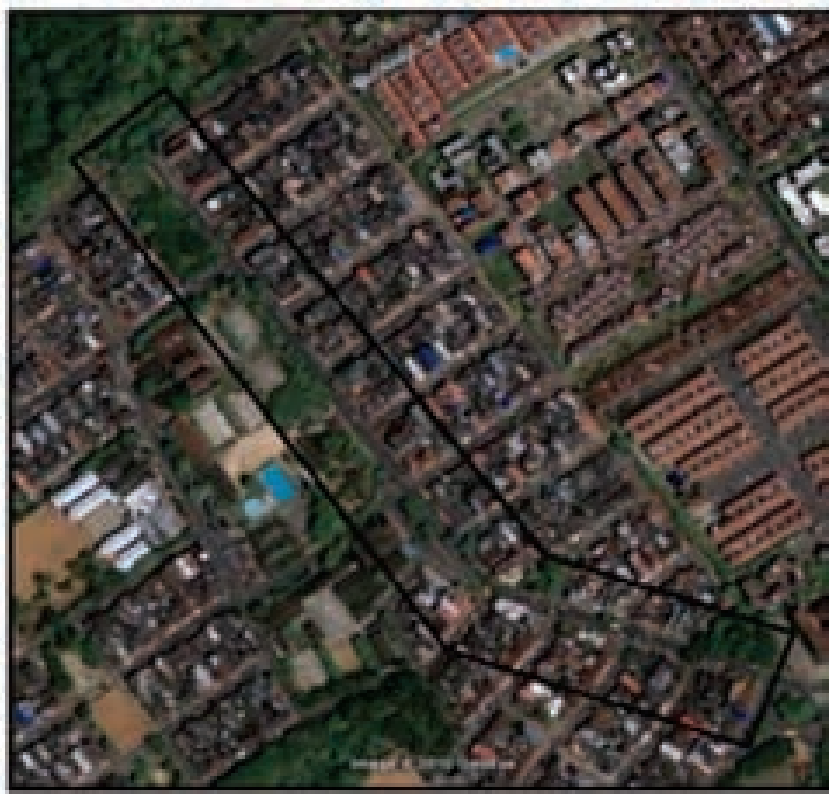

Imagen 6. Cra 2W Área de intervención. Fuente: Fotografía satelital Google Earth

Área de Intervención: Esta área está constituida como la Carrera $2 \mathrm{~W}$ del Barrio Mutis y los predios inmediatos a esta vía como muestra fundamental para el proceso de análisis, la cual representa el sector de mayor actividad y transformación del barrio, además de constituirse como el mayor sector de afectación por el proyecto del viaducto de la carrera novena. 


\section{ETAPA I: CONFIGURACIÓN ÁREA DE INFLUENCIA}

Durante la primera etapa denominada área de influencia se analizó inicialmente un área de mayor escala, es decir, Bucaramanga y el entorno inmediato del Barrio Mutis como área de referencia, la cual hace parte de un nivel de análisis general, necesario para comprender esta etapa. Según la localización y delimitación de las áreas analizadas, el área de influencia corresponde al bario Mutis, en donde se estudió su configuración (origen y principios ordenadores de diseño).

\section{CONFIGURACIÓN HISTÓRICA DE BUCARAMANGA Y ORIGEN DEL BARRIO MUTIS}

\section{$1908-1928$}

El desarrollo del sur de la Meseta se produce a partir los ejes viales de conexión con Floridablanca y Girón. En 1908 estos eran incipientes, pero hacia 1928 comienzan a mostrar una ocupación sobre los ejes viales, sobre todo en la Concordia, auspiciado por la familia Trebert, dueños de la Hacienda la Bucaramanga, hoy Barrio San Miguel (Ver Imagen 7.)

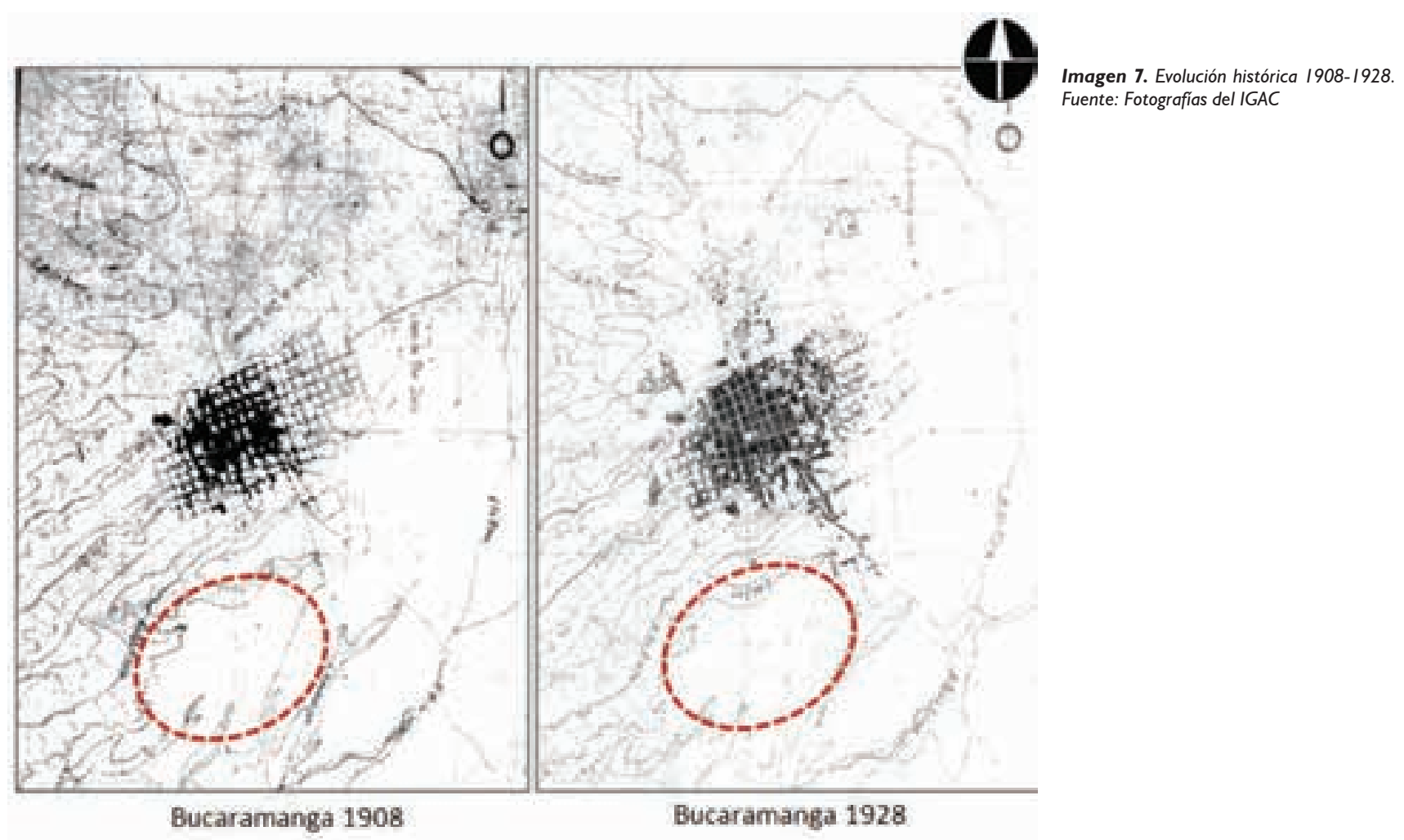

$1938-1948$

A partir de la década del cuarenta la ciudad se extiende sobre sus cuatro puntos cardinales. El sur se torna importante por la construcción del aeropuerto Gómez Niño y se vislumbra la incorporación de nuevos suelos urbanos (Ver Imagen 8.) 
Imagen 8. Evolución histórica 1938-1948. Fuente: Fotografías del IGAC

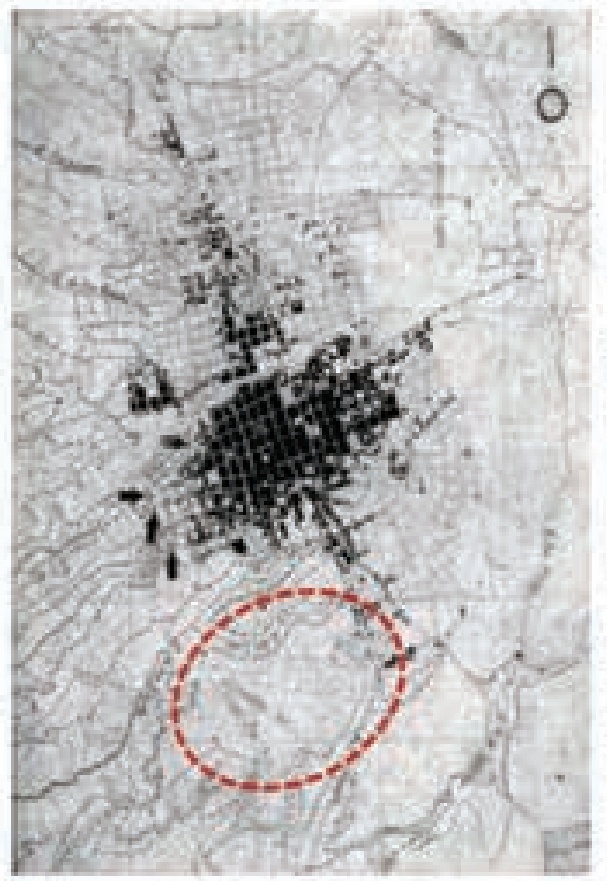

Bucaramanga 1938

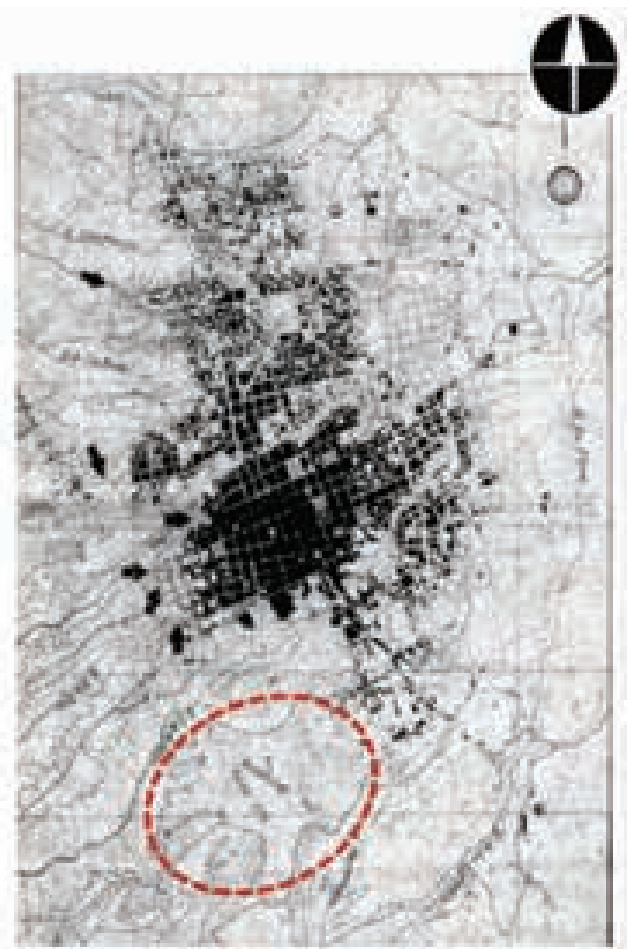

Bucaramanga 1948

\section{$1952-\mid 965$}

Aunque aún no se produce la construcción del Barrio Mutis, los suelos restantes cobran vigor a la luz de las intervenciones tanto de vivienda pública como privada: La Victoria, San Miguel, la conexión de La Concordia con Sotomayor, son prueba suficiente que el desarrollo urbano marcará nuevos derroteros (Ver Imagen 9.)

Imagen 9. Evolución histórica 1952-1965. Fuente: Fotografías del IGAC

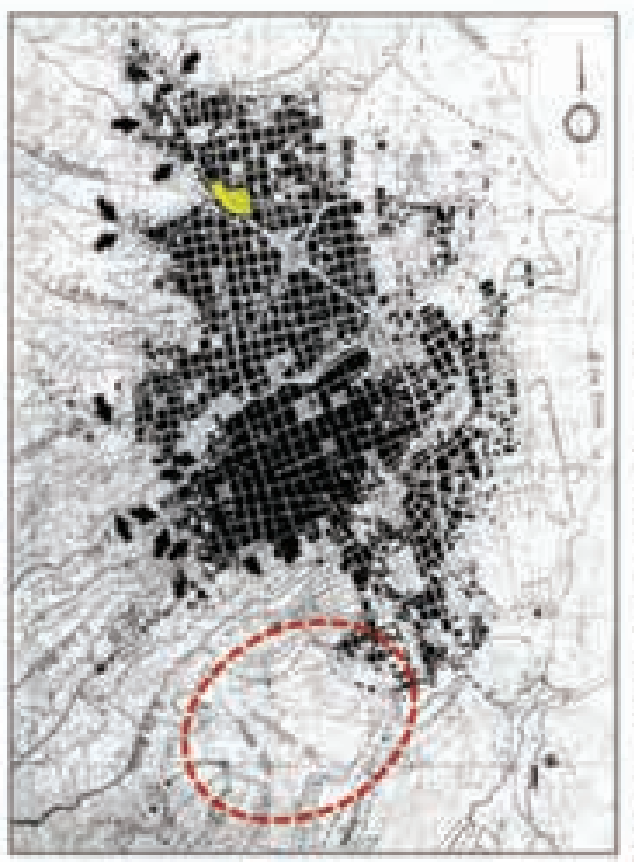

Bucaramanga 1952

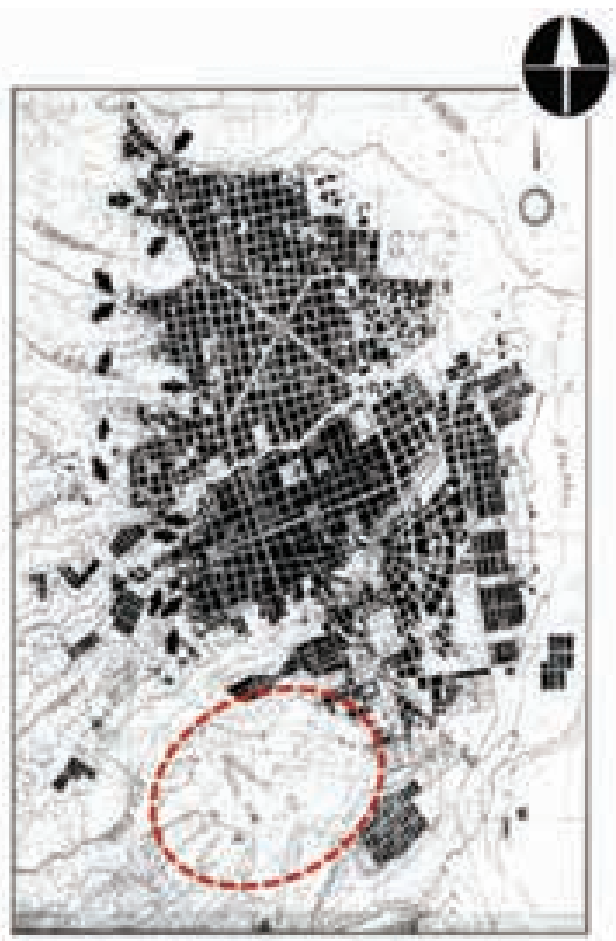

Bucaramanga 1965 
Los cambios producidos en este periodo son vertiginosos:

- Al tiempo que opera el aeropuerto, se construye el Barrio Mutis.

- El traslado del aeropuerto hará que se transformen los usos del suelo en residenciales.

- Se instala allí el proyecto Ciudadela Real de Minas y el Barrio servirá de enclave singular en el territorio.

- Hacia los años noventa se produce la consolidación urbana y se extiende el tejido urbano hacia el occidente sobre la misma franja, convirtiendo al Barrio Mutis en un elemento de enlace entre la ciudad consolidada y los nuevos desarrollos (Ver Imagen 10.)

El Barrio Mutis se implantó sobre un predio con un área de 23,6 hectáreas ubicado en la Granja Turbay, la cual compró el ICT. El proyecto está constituido por 33 manzanas de vivienda en hilera, organizadas en 5 módulos, separados por sectores de espacio público (vías y parques), en forma de G; contiene 1079 viviendas unifamiliares de dos plantas, que se construirán en varias etapas, destinadas a empleados del municipio, algunos gremios como el de periodistas y para sectores populares en general. El Barrio Mutis fue el primer colonizador del Llano de los Ordóñez, factor que fue clave para el desarrollo posterior del corredor, por lo tanto se constituye como un barrio pionero de desarrollo territorial en Bucaramanga.

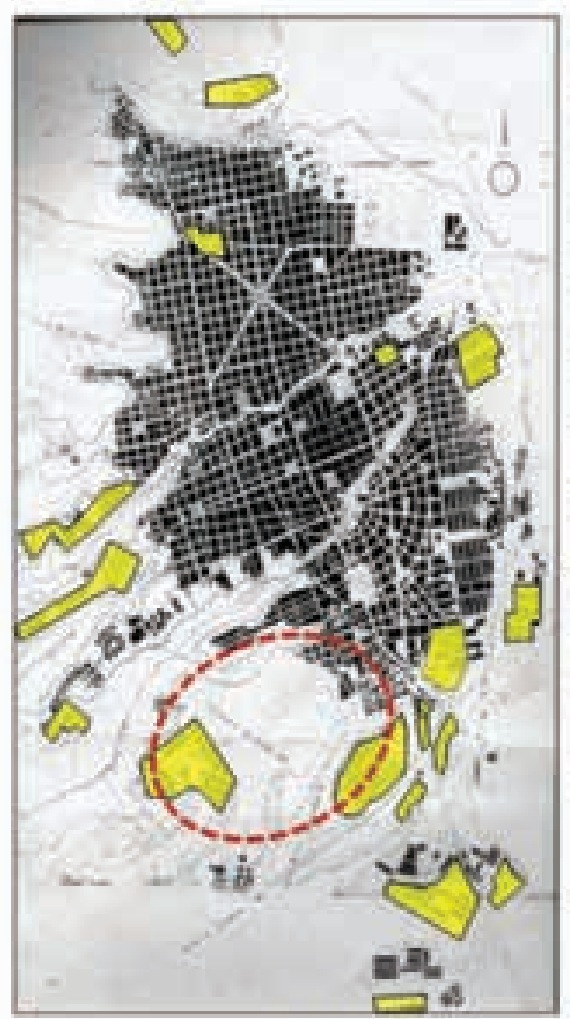

Bucaramanga 1970

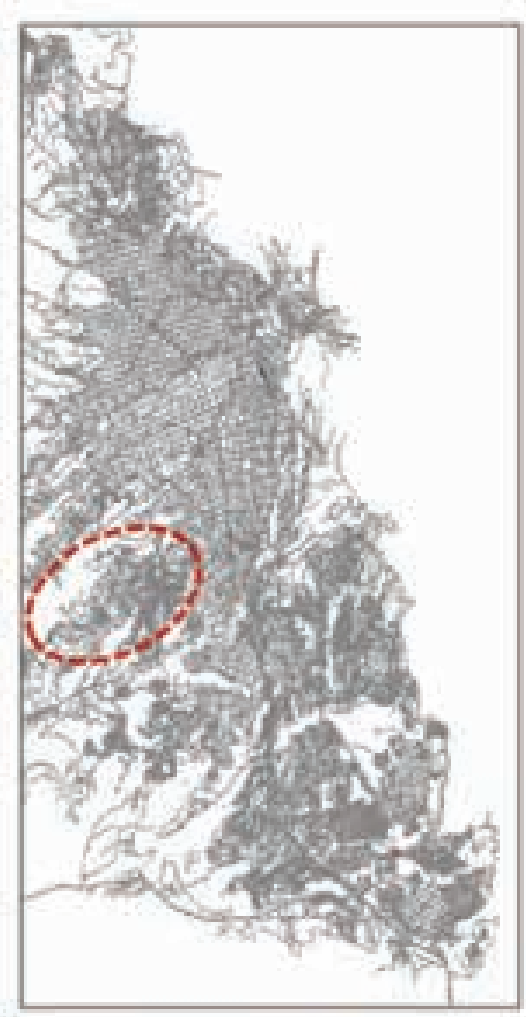

Bucaramanga 2010
Imagen 10. Evolución histórica 1970-2010 Fuente: Fotografías del IGAC 
Imagen II. Origen del área de influencia. Fuente: Fotografias aéreas IGAC Bucaramanga

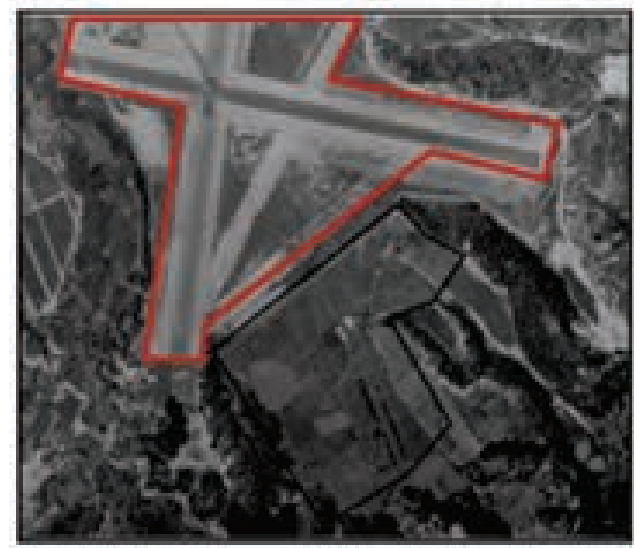

- Avcopueno Gomez hifio Barno Mutis aflos 60's

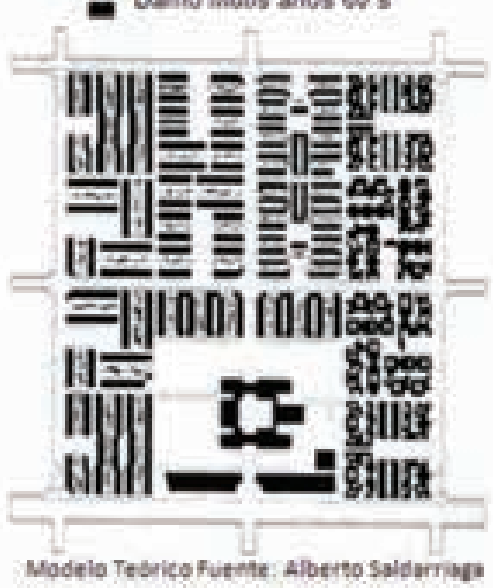

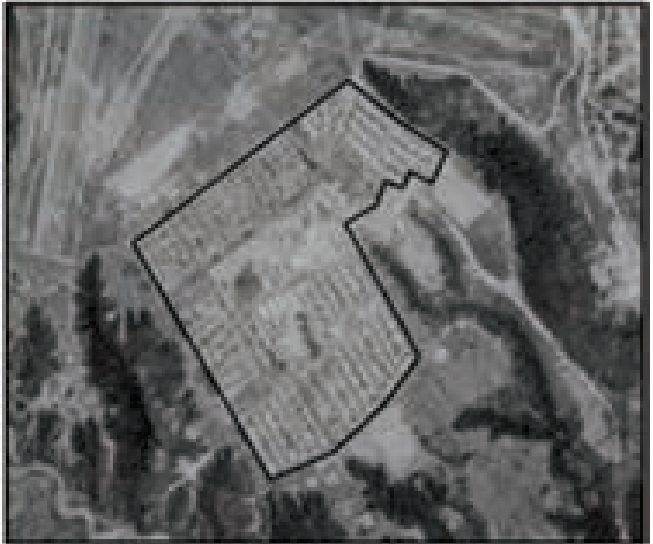

- Earrio Mutis alos 70's

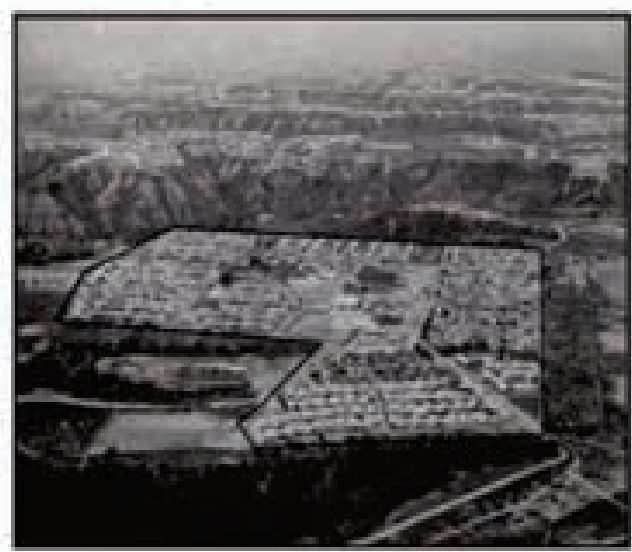

Vista atres Sur Nerte Barrio Muts

- Aspectos negativos originales: Inicialmente el barrio se localizó en el remate de la pista del Aeropuerto Gómez Niño, experimentaba problemas como el ruido, el peligro natural de las maniobras de vuelo, distancia remota con respecto al centro de la ciudad, problemas de accesibilidad.

- Aspectos positivos: Gracias al cierre del aeropuerto, al poco tiempo de ser proyectado el barrio, la problemática fue convertida en oportunidad y se consolidó como un proyecto producto de la buena planeación urbana.

\section{Principios ordenadores}

El urbanismo que se utilizó en el proyecto se anticipó al Modelo Teórico Propuesto en el estudio de Normas Mínimas de Urbanización, Servicios Públicos y Servicios Comunitarios de 1972, en el cual se propone la acción simultánea entre la vivienda y los servicios comunales, por esta razón podría inferirse que tiene un argumento claro de composición, lo que hace de este proyecto un modelo de barrio para la ciudad. El Barrio Mutis es en sentido estricto, un modelo planificado de unidad vecinal, cuyos elementos están en perfecta armonía: espacio público adecuado, accesibilidad vehicular a todas las viviendas y equipamientos dotacionales completos. 


\section{CARACTERIZACIÓN ACTUAL DEL BARRIO}

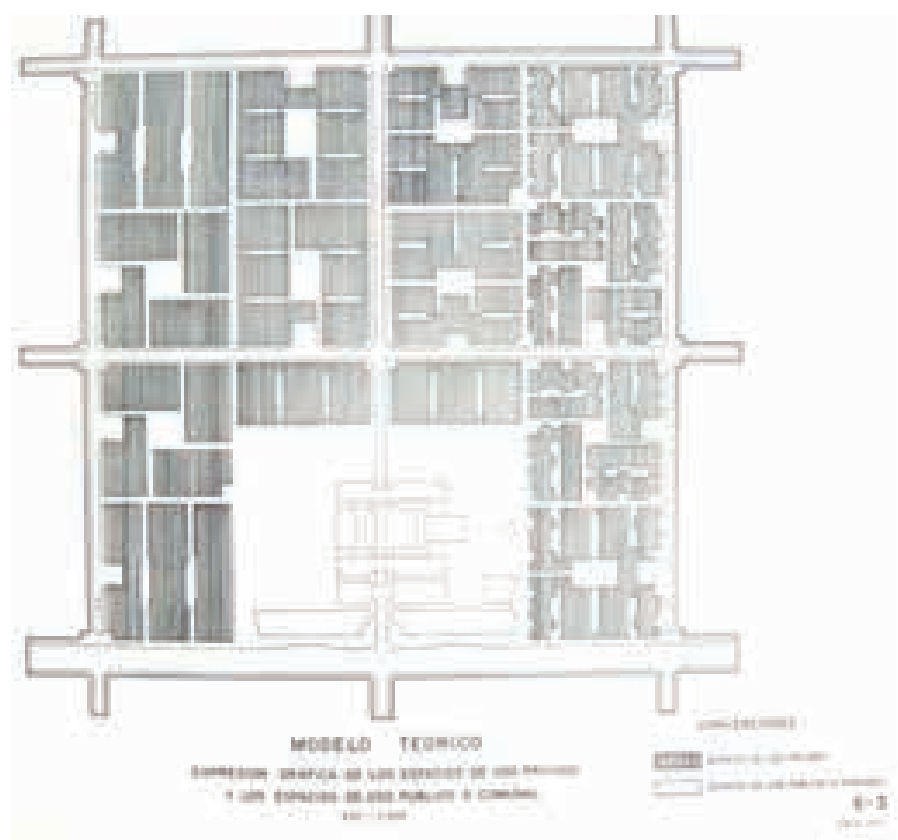

Imagen 12. Principios ordenadores Fuente: Instituto de Crédito Territorial, Departamento Administrativo de Planeación Distrital,

Departamento Administrativo de Planeación Nacional. Estudio de Normas Mínimas de urbanización, servicios públicos y servicios comunitarios. Bogotá.
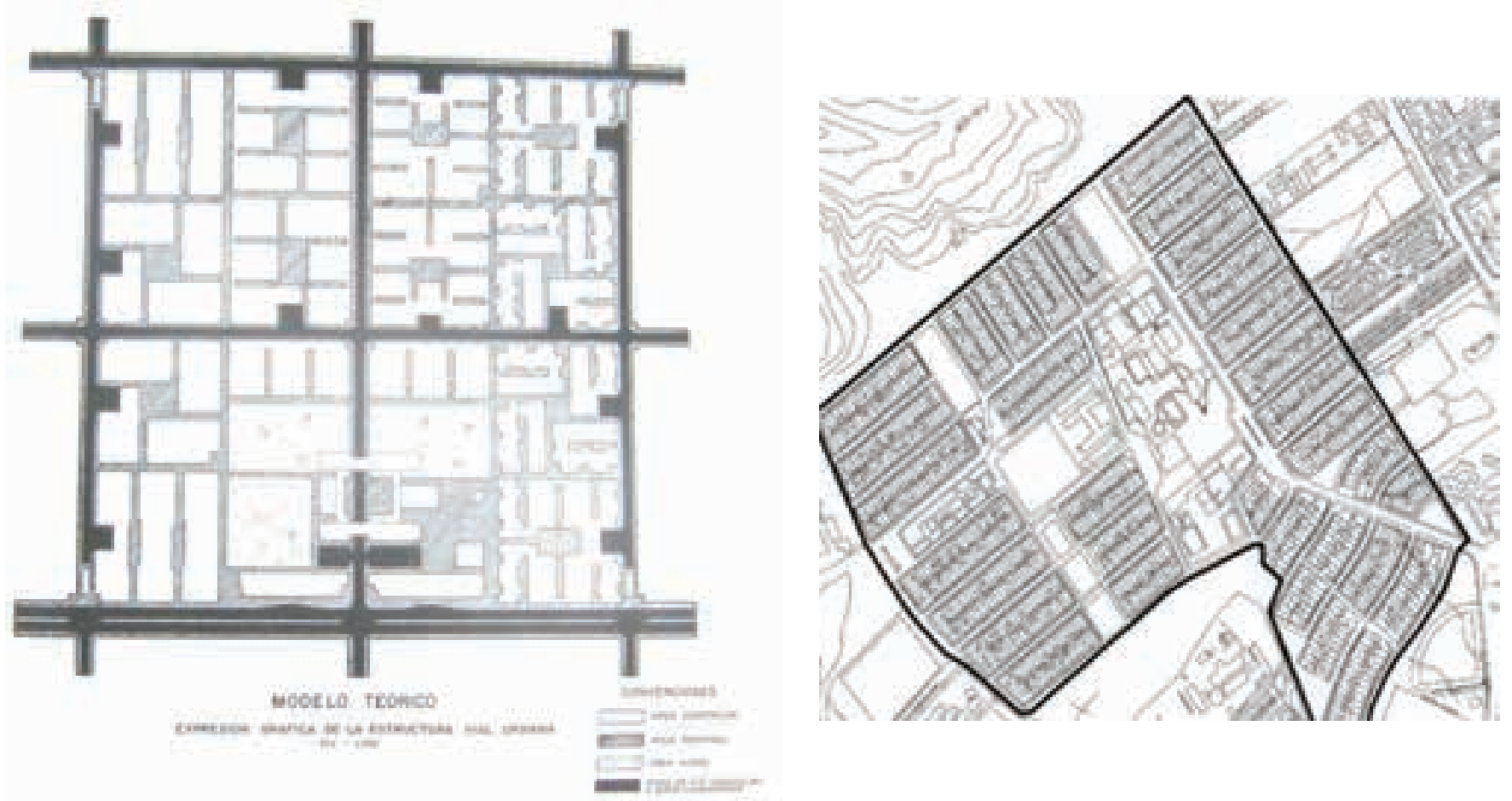


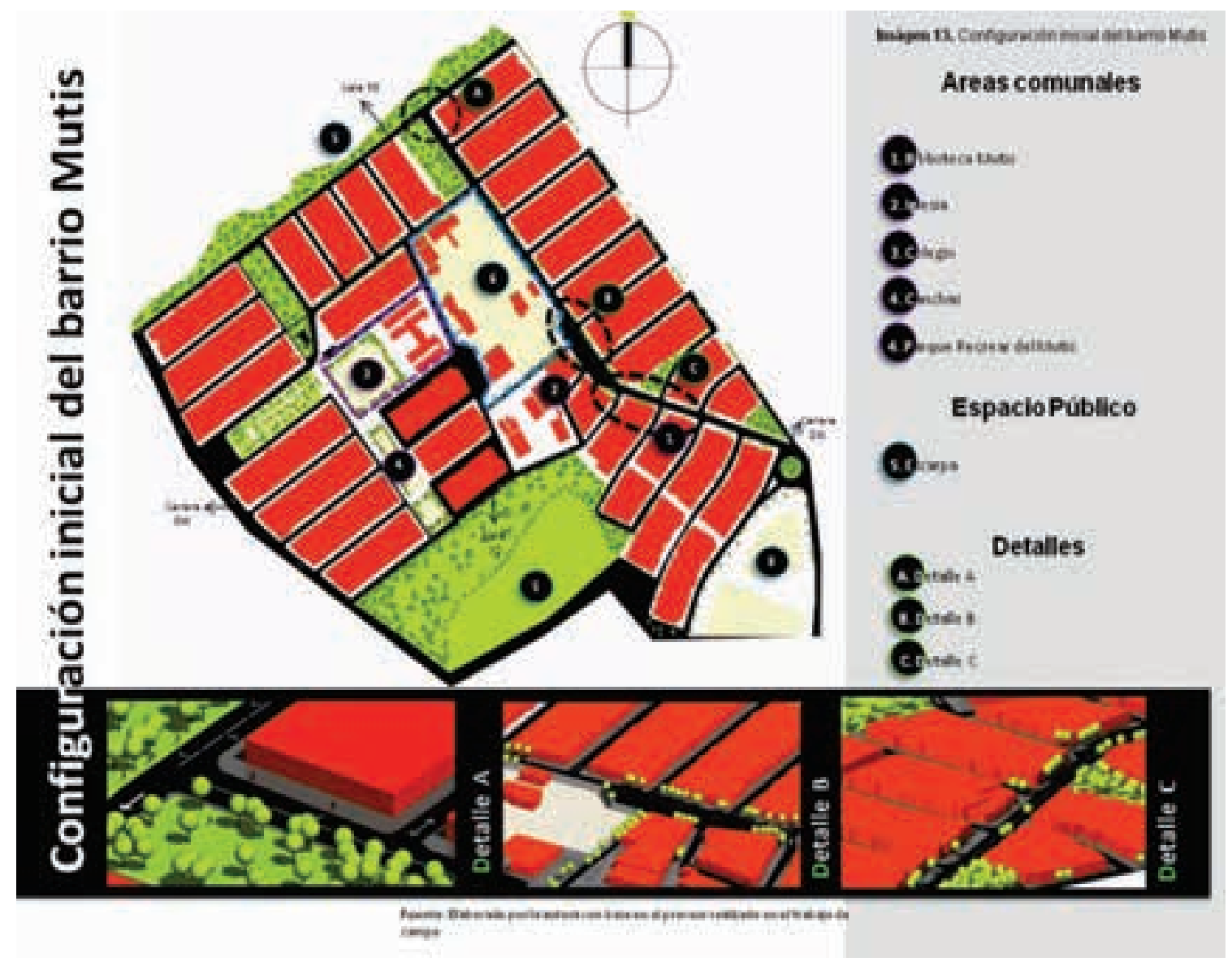

\section{Caracterización actual del barrio Mutis}

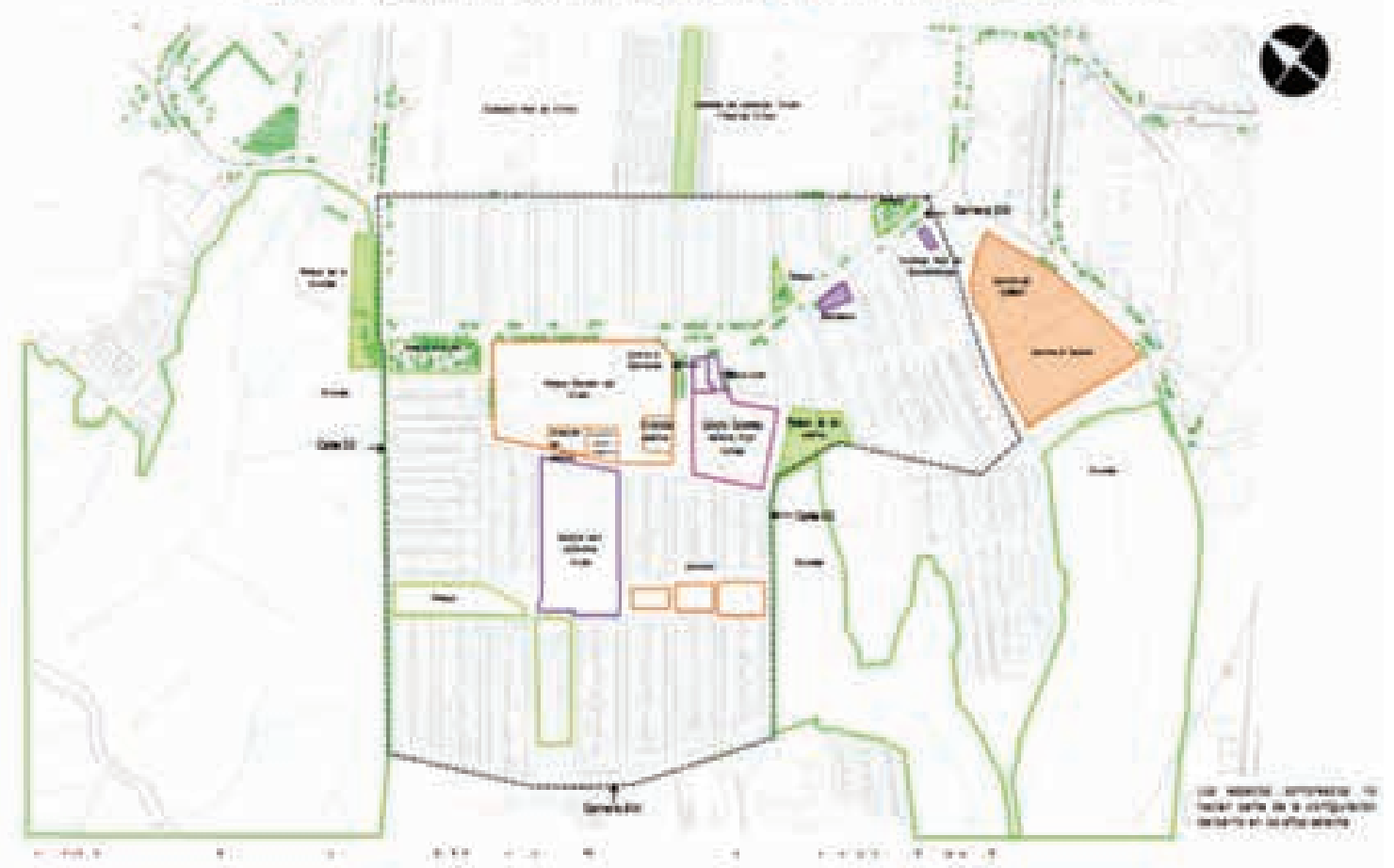




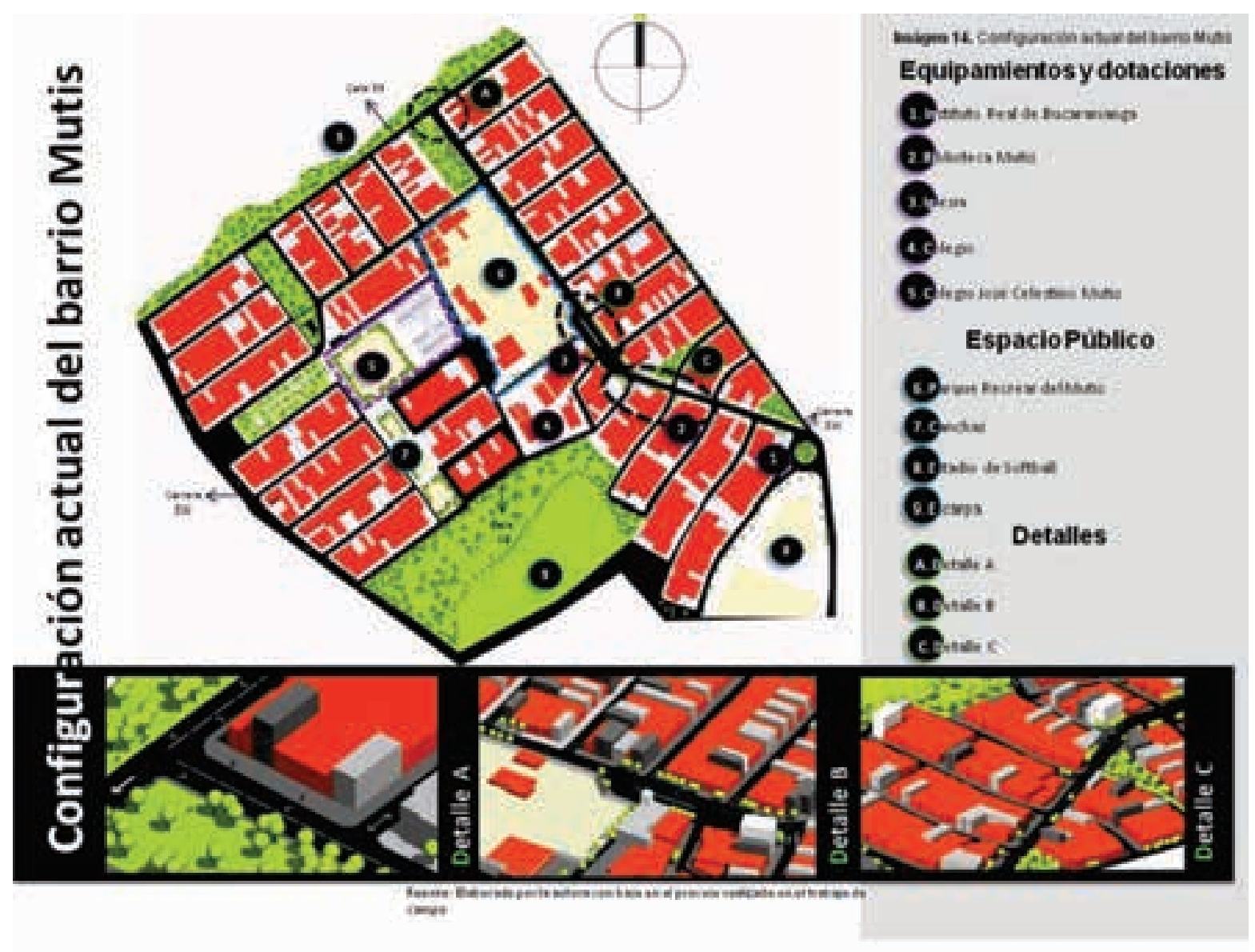

\section{CATEGORÍAS DE ANÁLISIS ÁREA DE INFLUENCIA}

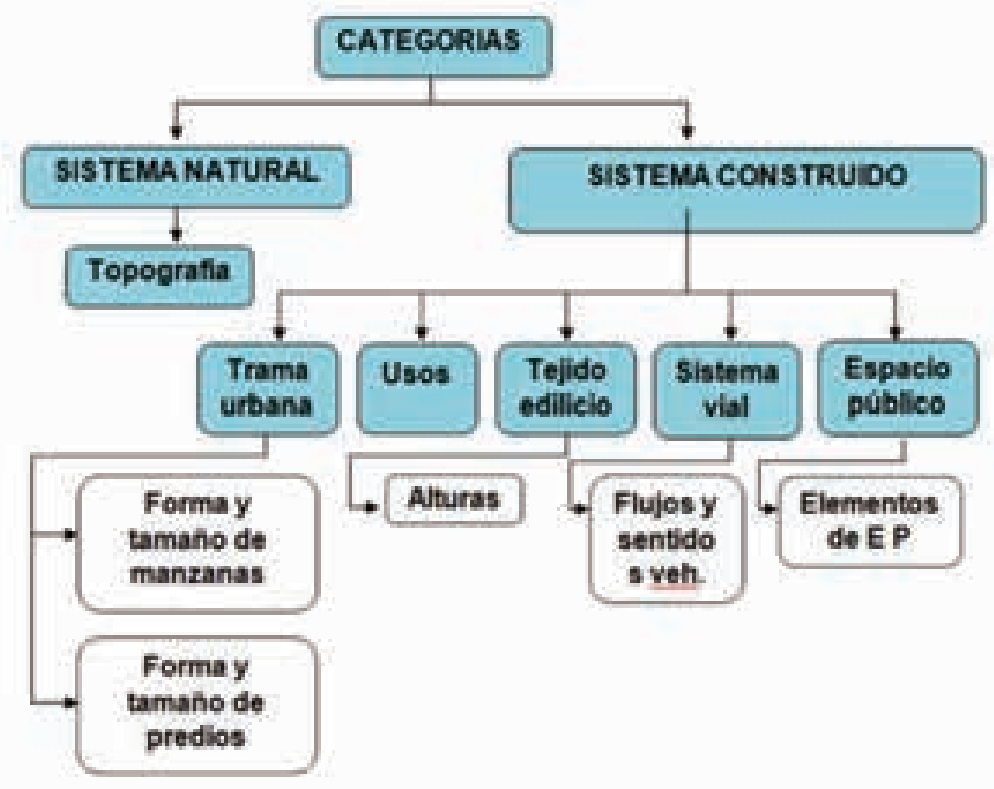

Imagen 15. Categorías de análisis del área de influencia Fuente: Elaborado por la autora con base en el análisis y selección de información 


\section{Sistema natural}

\section{Topografía}

\section{Descripción}

I. El barrio se encuentra implantado sobre un terreno con una pendiente mínima.

2. La topografía del sector es uniforme, solo cambia en la parte de la escarpa occidental.

3. La escarpa tiene amenazas por remoción de masas y necesita acciones de preservación, por lo tanto, se requiere un estudio y tratamiento especial para realizar un diseño posterior como complemento de las necesidades de los habitantes del barrio.

4. Evaluación - proyección: El terreno se encuentra rodeado por la escarpa y ésta, gracias a su gran pendiente, tiene una excelente visual que puede ser aprovechada a la hora de realizar un posterior diseño urbano que permita fortalecer los aspectos positivos del barrio.

Imagen 16. Topografía. Fuente: Elaborado por la autora con base en información analizada en el trabajo de campo

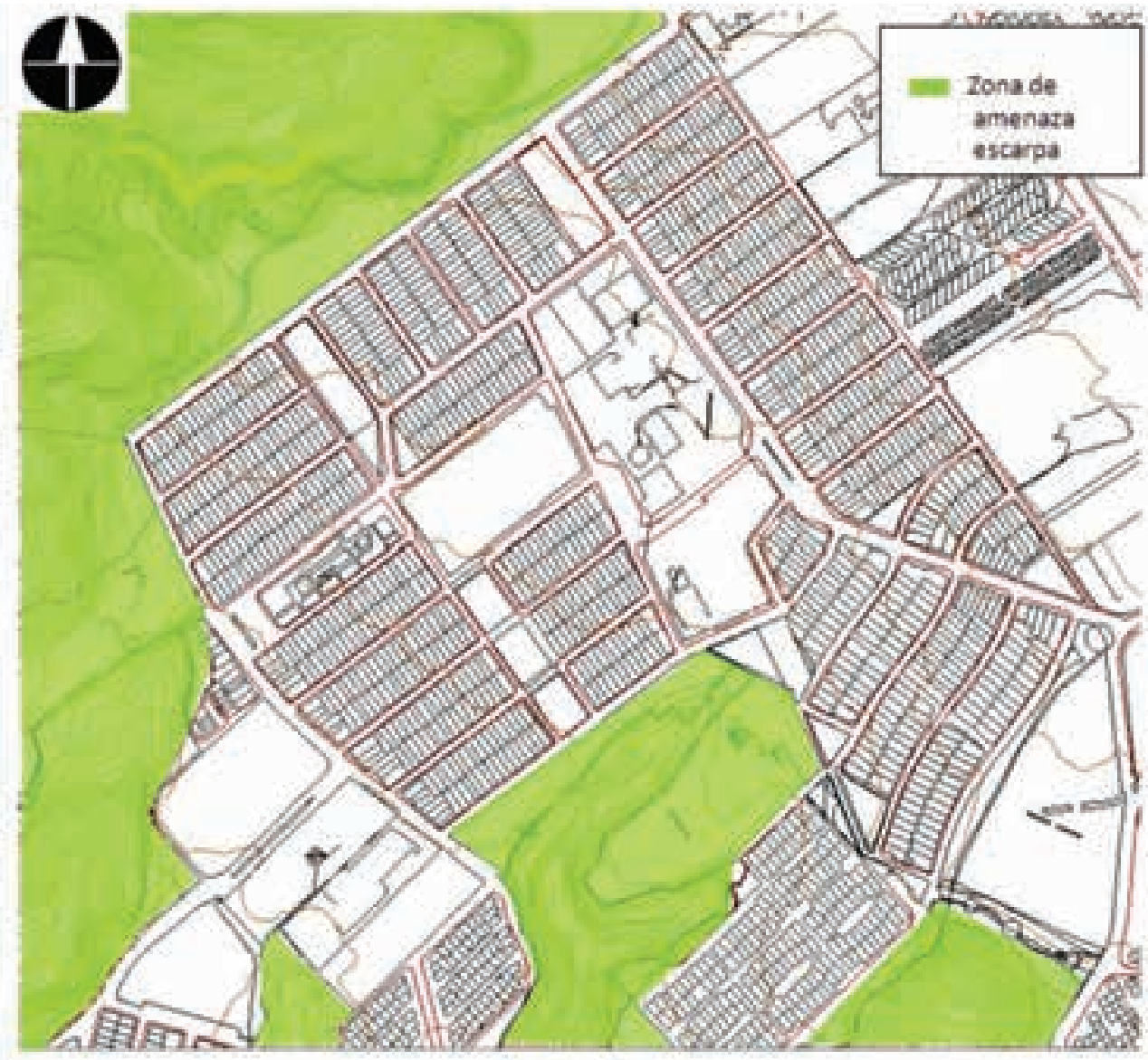




\section{Sistema construido}

\section{Trama Urbana}

- Forma y tamaño de manzanas

- Descripción: El sector posee una trama urbana conformada por manzanas de tres clasificaciones por tamaño: las de mayor tamaño tienen un área aproximada de $6257 \mathrm{~m} 2$ y se encuentran localizadas hacia la parte suroriental, las manzanas de tamaño intermedio poseen un área de $4673 \mathrm{~m} 2$ aproximadamente y las de menor tamaño cuentan con un área aproximada de $3497 \mathrm{~m} 2$; además de esta clasificación se encontró que el barrio Mutis cuenta con manzanas uniformes y algunas que no poseen la misma uniformidad, sin embargo, el cambio no es muy representativo.

- Explicación: La diferencia que existe en el tamaño de las manzanas responde a los ejes principales de diseño, además de la organización de los ejes viales del proyecto; en cuanto a la uniformidad de las manzanas se puede inferir que el proyecto contempla varias tipologías de vivienda, en las cuales varía el patio de ropas, de acuerdo a las necesidades establecidas por el diseñador del proyecto.

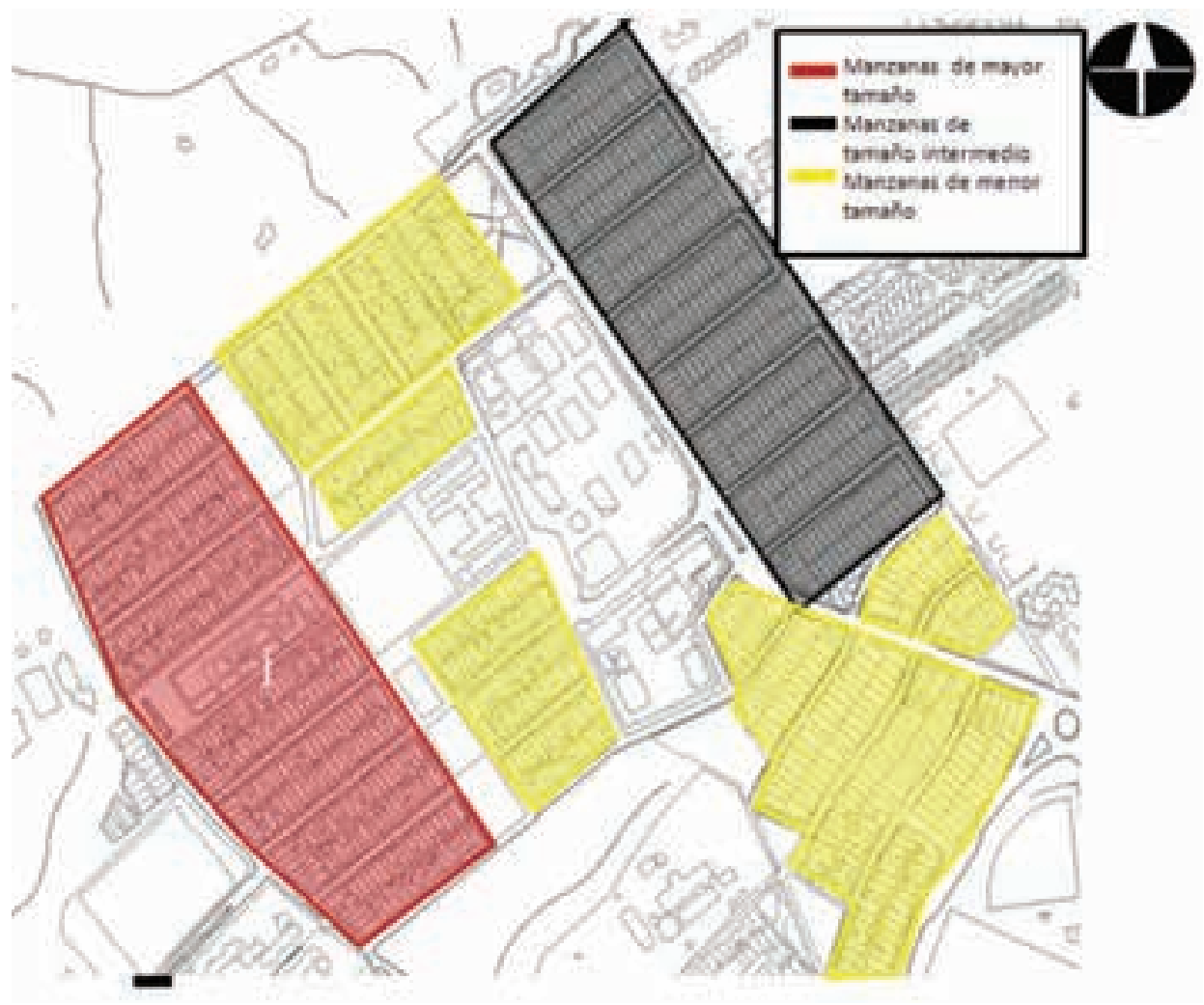

Imagen I7. Forma y tamaño de las manzanas. Fuente: Elaborado por la autora con base en información analizada en el trabajo de campo 
- Forma y tamaño de los predios

- Descripción: El sector posee una trama urbana conformada por predios de tres clasificaciones de acuerdo a su tamaño: los de mayor tamaño tienen un área aproximada de $148 \mathrm{~m}^{2}$ y se encuentran localizados hacia la parte suroriental, los predios de tamaño intermedio poseen un área de $97 \mathrm{~m}^{2}$ aproximadamente y los de menor tamaño cuentan con un área aproximada de $65 \mathrm{~m}^{2}$; además de esta clasificación se encontró que el barrio Mutis, cuenta con predios uniformes, aunque algunos no conservan la misma regularidad, el cambio no es muy significativo.

- Explicación: La diferencia que existe en el tamaño de los predios responde a los ejes principales de diseño, además de la organización de los ejes viales del proyecto; en cuanto a la uniformidad de los predios se puede inferir que el proyecto contempla varias tipologías de vivienda, en las cuáles varía el patio de ropas, de acuerdo a las necesidades establecidas por el diseñador del proyecto.

\section{Usos generales}

- Descripción: El Barrio Mutis se compone principalmente de un uso residencial, uso que se ha transformado a través de su evolución en uso mixto que contempla la vivienda y el comercio, este fenómeno se presenta con mayor fuerza en los predios ubicados sobre los ejes vehiculares y peatonales de mayor flujo y actividad; el sector cuenta con zonas de servicios en las cuales se encuentran equipamientos y dotaciones ubicadas en puntos estratégicos previamente planificados, además de zonas verdes para la recreación y esparcimiento de la comunidad. Es importante resaltar que los ejes de mayor flujo del sector configuran un aspecto fundamental en la transformación de los usos del barrio.

Imagen 18. Forma y tamaño de los predios. Fuente: Elaborado por la autora con base en información analizada en el trabajo de campo

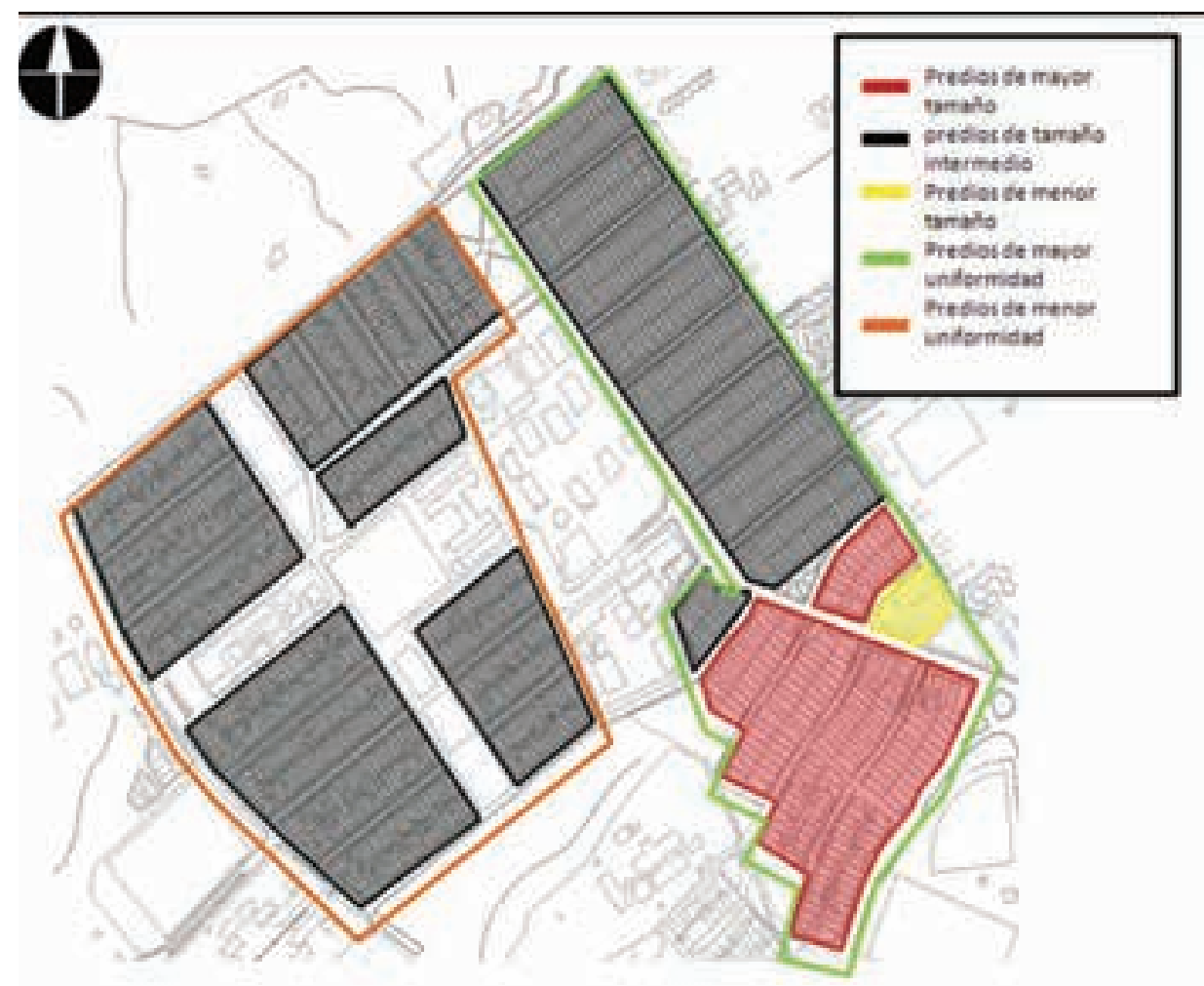




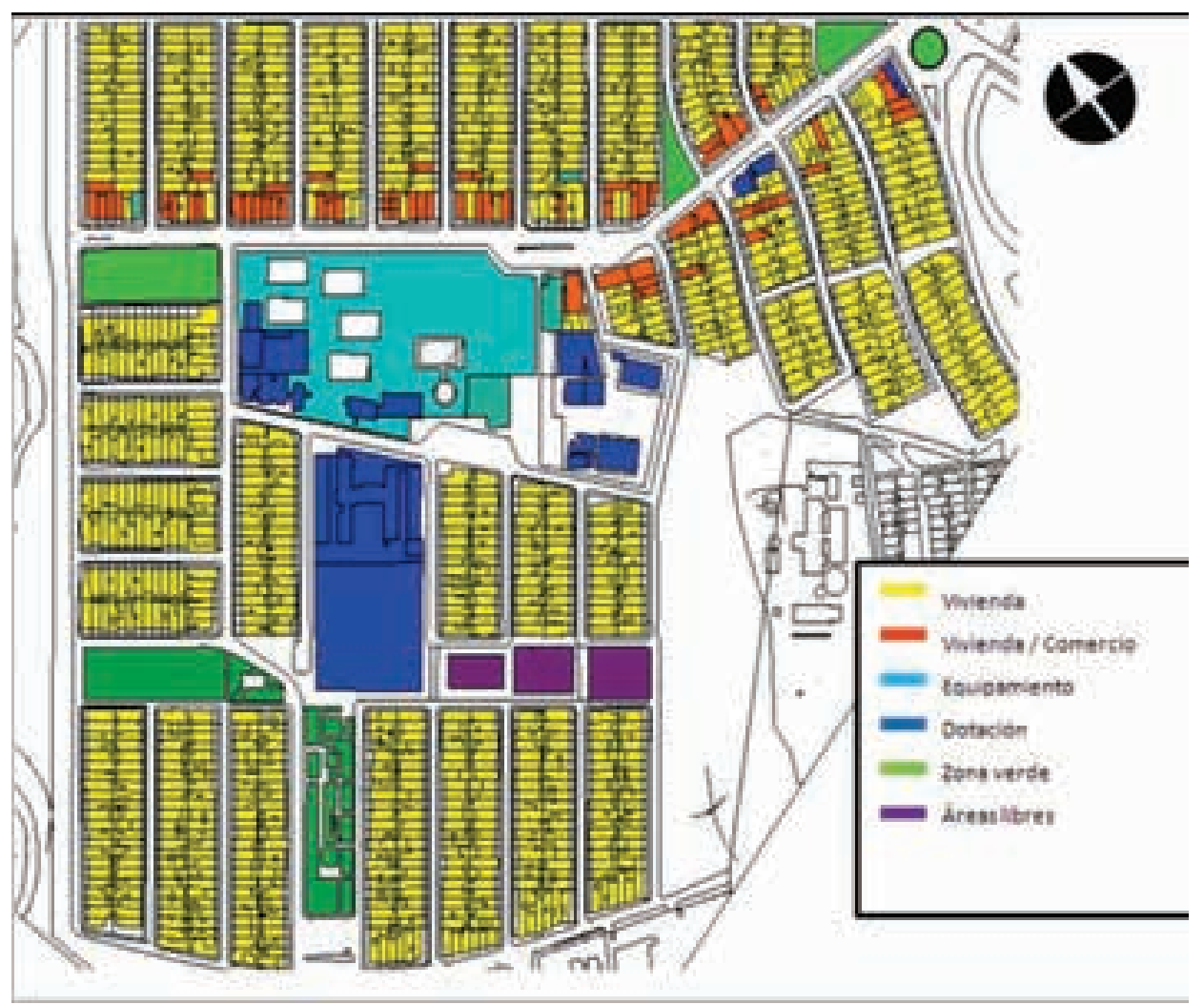

Imagen 19. Usos generales. Fuente: Elaborado por la autora con base en información analizada en el trabajo de campo

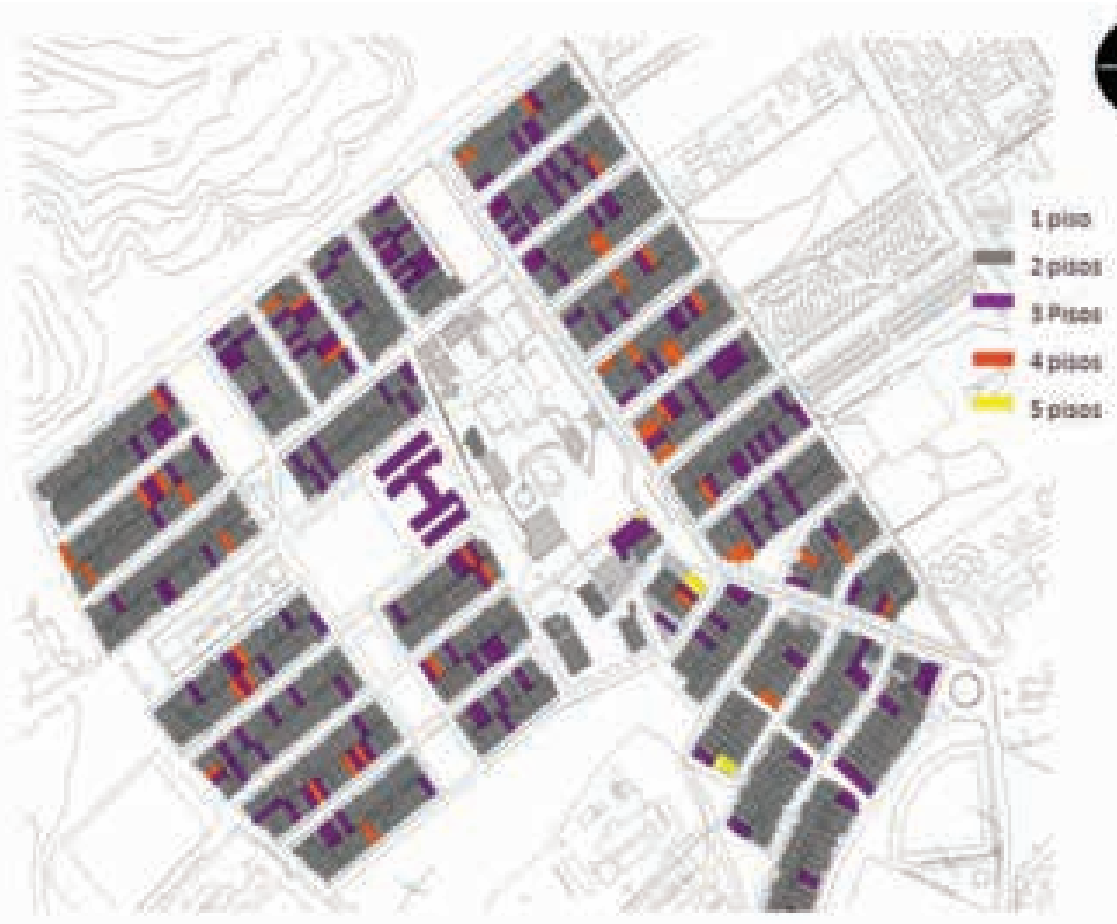

Imagen 20. Alturas Barrio Mutis. Fuente: Elaborado por la autora con base en información analizada en el trabajo de campo 


\section{Tejido Edilicio - Alturas}

- Descripción: Según la información analizada por medio del trabajo de campo se puede inferir que en el sector, actualmente predominan las alturas de 2 pisos, sin embargo, es importante resaltar que existen viviendas con uso mixto (residencial/ comercial) que tienen alturas superiores, los rangos más comunes son entre 3 y 5 pisos en este tipo de edificaciones, además según el análisis se observa que los predios de mayor altura por lo general se ubican cerca al área de influencia (Carrera 2W) y en los centros de manzana.

- Explicación: La razón por la cual se encuentra mayor cantidad de predios de alturas de 2 pisos se debe a que así fueron proyectados los predios en donde sólo se manejaría vivienda de esa altura, sin embargo, se ha aumentado la altura especialmente en uso mixto lo que indica que se crece en altura debido a la necesidad de ocupación de los habitantes que quedaron desplazados del primer piso.

- Evaluación y Proyección: Existe una tendencia a incrementarse la altura en los predios ubicados sobre la vía de mayor actividad, esto da cuenta además de la falta de equipamientos comerciales que estén adecuados para ese uso, además es evidente el aumento de densidad poblacional, lo que requiere más espacio para alojarse y residir en el sector, de ahí que se observa en el plano el aumento de altura que se da hacia los centros de manzana.

Imagen 2I. Volumetría de alturas Barrio Mutis. Fuente: Elaborado por la autora con base en la información recogida en campo

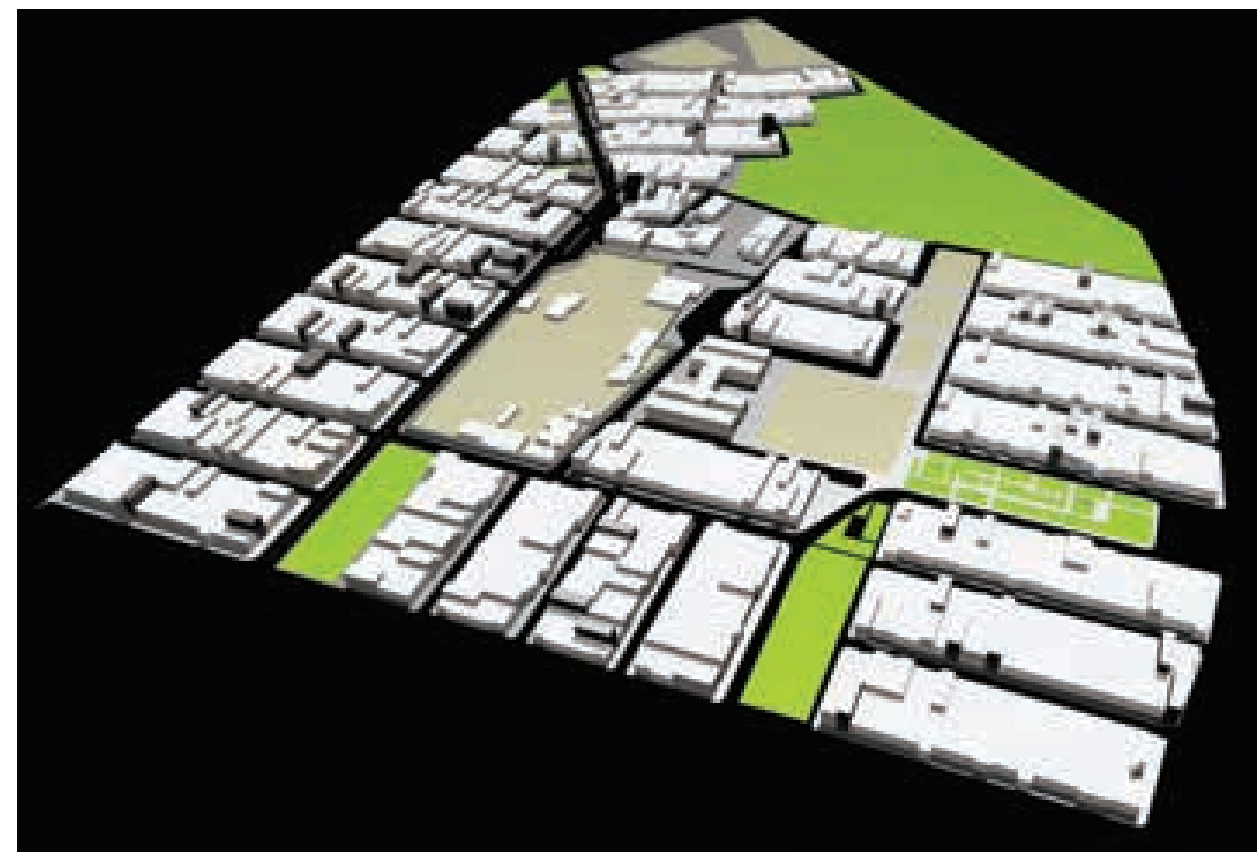




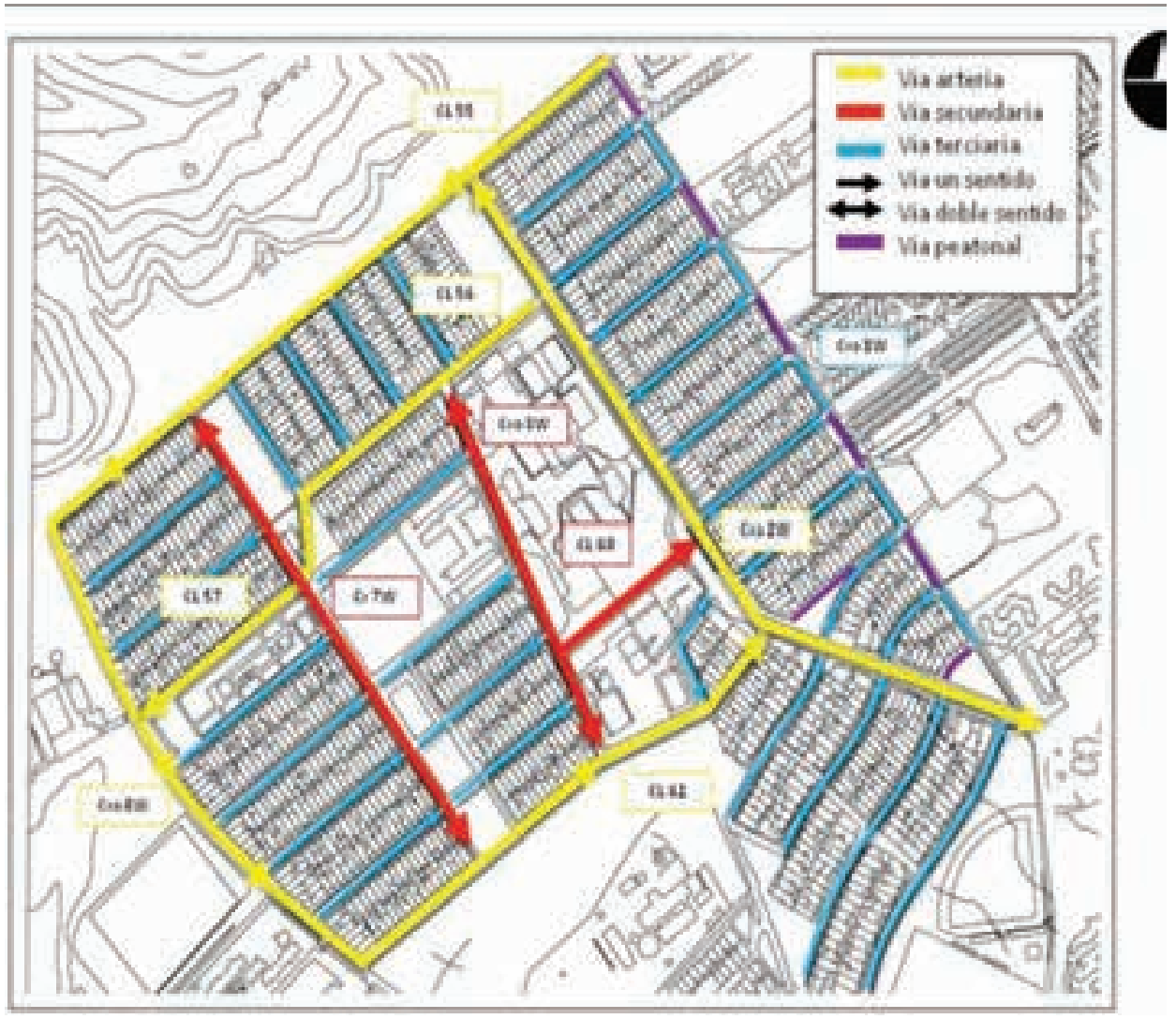

Imagen 22. Sistema vial Barrio Mutis.

Fuente: Elaborado por la autora con base en

información analizada en el trabajo de campo

\section{Sistema vial - Flujos y sentidos}

- Descripción: Dentro del sistema vial se encuentran 3 vías arterias, debido a su flujo vehicular y a su actividad consecuencia de dicho tráfico, donde el principal eje articulador es la Carrera 2W (área de intervención), en el diagrama de flujos se observa cómo los otros ejes viales arteriales tienen relación con esta carrera, los ejes secundarios se encargan de articular a los terceros, que produce todo un ciclo y una conectividad clara; en general, el sistema vial del barrio Mutis es un modelo imitable ya que hace que el barrio funcione autónomamente y de manera efectiva, lo cual permite tener una buena accesibilidad y excelentes conexiones, por esta razón casi todas las rutas de transporte público pasan por el sector y aún así no se genera un caos vehicular significativo. Existen 2 puntos de conflicto los cuales se presentan por la unión de los 2 ejes arteriales y por el recibo del flujo vehicular de la calle 65 .

\section{Elementos del espacio público}

- Descripción: El sector se encuentra rodeado de la escarpa, lo que permite junto con los parques del barrio, constituir espacios para el libre esparcimiento de los visitantes del barrio y sus habitantes, además, gracias a la planeación con base en un modelo de ciudad, se tienen en cuenta espacios para la recreación y el libre desplazamiento de la comunidad. 
Imagen 23. Componentes del espacio público. Fuente: Elaborado por la autora con base en información analizada en el trabajo de campo

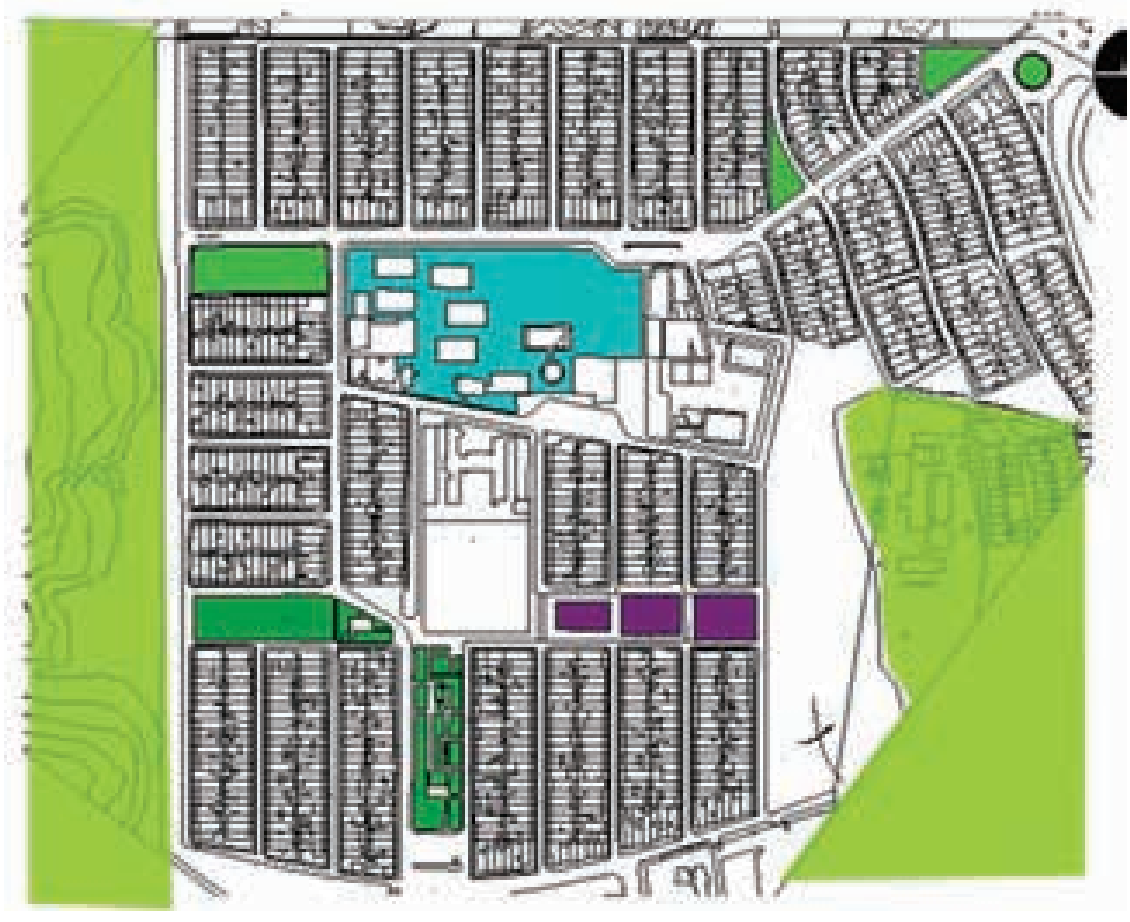

CONCLUSIONES ETAPA I

Ya que el Barrio Mutis se proyectó a partir de principios básicos en los cuales se logra una relación directa entre la vivienda y los servicios comunales que suplan las necesidades básicas de los residentes del barrio, se infiere que fue planificado, tiene un argumento claro y lógico de composición, y fue pensado principalmente para el bienestar de sus habitantes, lo que hace de este barrio un ejemplo en la ciudad de Bucaramanga.

Otro motivo por el cual el barrio Mutis se considera una propuesta afortunada es el trabajo comunitario, el cual existió desde el inicio de la construcción de las viviendas, ya que los mismos habitantes del barrio, trabajaron de manera conjunta y organizada en la culminación del proyecto.

Es importante resaltar que el barrio presenta una actividad fluida, peatonal y vehicularmente gracias a las dimensiones generosas de las vías y el espacio público del barrio, aspecto común en la composición de las unidades barriales de las principales ciudades del país.

En la composición del barrio se resalta otro aspecto importante, la dimensión y el área del espacio público con relación al área construida, al respecto, se estima que el porcentaje de espacio público es de $35 \%$ y de área construida es de $73 \%$ aproximadamente, por lo cual se infiere que el barrio es generoso con respecto al área libre para sus habitantes.

Desde el origen del barrio hasta hoy, los cambios más representativos que muestran la transformación de la sociedad sobre el territorio según sus necesidades, son el cambio de uso y tipología de viviendas y el aumento de las alturas de las mismas, dentro de las zonas de mayor transformación se encuentra la Carrera $2 \mathrm{~W}$ consolidada como el el eje de mayor actividad y transformación dentro del Mutis. 


\section{BIBLIOGRAFÍA}

LEFEBVRE, Henry. El derecho a la ciudad. Barcelona, Ediciones Península 1978

MAYA PÉREZ, Esther; CERVANTEZ BORJA, Jorge F. La producción de vivienda del sector privado y su problemática en el municipio de Ixtapaluca. México, Universidad Autónoma de México, 2005

POBLETE TOELG, Carolina. Proyecto de mejoramiento urbano y habitacional, Chile, 2005

RUEDA GÓMEZ, Néstor José; GÓMEZ SUÁREZ, José Alejandro. Viejas estructuras nuevas oportunidades. Escenarios Urbanos. Bucaramanga, Universidad Santo Tomás, 2007

VÁZQUEZ, Antonio. Los aportes de Lefebvre a la geografía urbana. Un corpus teórico para entender las nuevas espacialidades. México, Colegio de Geografía UNAM, 2009

CARVAJALINO, Hernando. La experiencia bogotana: del barrio obrero al lote con servicios. Bogotá, Universidad Nacional de Colombia, SMD. p. 155

\section{FUENTES INSTITUCIONALES}

Guía Práctica de la movilidad peatonal urbana, Bogotá, Instituto de Desarrollo Urbano de Bogotá IDU.

Manual para el diseño y construcción del espacio público de Bucaramanga. (MEPB) Bucaramanga, Alcaldía municipal de Bucaramanga, Oficina Asesora de Planeación. 